\title{
Inactivation of the GATA Cofactor ZFPM1 Results in Abnormal Development of Dorsal Raphe Serotonergic Neuron Subtypes and Increased Anxiety-Like Behavior
}

\author{
${ }^{\circledR}$ Laura Tikker, ${ }^{1}$ Plinio Casarotto, ${ }^{2}$ Parul Singh, ${ }^{1}{ }^{\circledR}$ Caroline Biojone, ${ }^{2}{ }^{\circledR}$ T. Petteri Piepponen, ${ }^{3}$ Nuri Estartús, ${ }^{1}$ \\ ${ }^{\circledR}$ Anna Seelbach, ${ }^{1}$ Ravindran Sridharan, ${ }^{1}{ }^{\circledR}$ Liina Laukkanen, ${ }^{2}{ }^{\circledR}$ Eero Castrén, ${ }^{2}$ and ${ }^{\circledR}$ Juha Partanen ${ }^{1}$ \\ ${ }^{1}$ Molecular and Integrative Biosciences Research Programme, University of Helsinki, FIN-00014 Helsinki, Finland, ${ }^{2}$ Neuroscience Center - HiLife, \\ University of Helsinki, FIN-00014 Helsinki, Finland, and ${ }^{3}$ Division of Pharmacology and Pharmacotherapy, University of Helsinki, FIN-00014 \\ Helsinki, Finland
}

Serotonergic neurons in the dorsal raphe (DR) nucleus are associated with several psychiatric disorders including depression and anxiety disorders, which often have a neurodevelopmental component. During embryonic development, GATA transcription factors GATA2 and GATA3 operate as serotonergic neuron fate selectors and regulate the differentiation of serotonergic neuron subtypes of DR. Here, we analyzed the requirement of GATA cofactor ZFPM1 in the development of serotonergic neurons using Zfpm 1 conditional mouse mutants. Our results demonstrated that, unlike the GATA factors, ZFPM1 is not essential for the early differentiation of serotonergic precursors in the embryonic rhombomere 1 . In contrast, in perinatal and adult male and female Zfpm1 mutants, a lateral subpopulation of DR neurons (ventrolateral part of the DR) was lost, whereas the number of serotonergic neurons in a medial subpopulation (dorsal region of the medial DR) had increased. Additionally, adult male and female Zfpm1 mutants had reduced serotonin concentration in rostral brain areas and displayed increased anxiety-like behavior. Interestingly, female Zfpm1 mutant mice showed elevated contextual fear memory that was abolished with chronic fluoxetine treatment. Altogether, these results demonstrate the importance of ZFPM1 for the development of DR serotonergic neuron subtypes involved in mood regulation. It also suggests that the neuronal fate selector function of GATAs is modulated by their cofactors to refine the differentiation of neuronal subtypes.

Key words: anxiety; differentiation; dorsal raphe; embryo; serotonergic neuron; transcription factor

Significance Statement

Predisposition to anxiety disorders has both a neurodevelopmental and a genetic basis. One of the brainstem nuclei involved in the regulation of anxiety is the dorsal raphe, which contains different subtypes of serotonergic neurons. We show that inactivation of a transcriptional cofactor ZFPM1 in mice results in a developmental failure of laterally located dorsal raphe serotonergic neurons and changes in serotonergic innervation of rostral brain regions. This leads to elevated anxiety-like behavior and contextual fear memory, alleviated by chronic fluoxetine treatment. Our work contributes to understanding the neurodevelopmental mechanisms that may be disturbed in the anxiety disorder.

Received Sep. 20, 2019; revised Sep. 17, 2020; accepted Sep. 25, 2020.

Author contributions: L.T., P.C., P.S., T.P.P., and J.P. designed research; L.T., P.C., P.S., C.B., T.P.P., N.E., A.S., R.S., and L.L. performed research; L.T., P.C., P.S., C.B., T.P.P., N.E., A.S., R.S., L.L., E.C., and J.P. analysed data and wrote the paper.

This work has been supported by the Jane and Aatos Erkko Foundation, the Sigrid Juselius Foundation, and the Academy of Finland. L.T. was funded by the Integrative Life Science (ILS) doctoral program at the University of Helsinki, the Orion Research Foundation sr, and The Company of Biologists Disease Models \& Mechanisms. We thank Outi Kostia for excellent technical assistance. We also thank Wolfgang Wurst for the $E n 1^{\text {Cre }}$ mice, Claus Nerlov for the Zfpm $1^{\text {flox }}$ mice, and Stuart Orkin for the Zfpm $2^{\text {flox }}$ mice.

The authors declare no competing financial interests.

Correspondence should be addressed to Juha Partanen at juha.m.partanen@helsinki.fi.

https://doi.org/10.1523/JNEUROSCI.2252-19.2020

Copyright $\odot 2020$ the authors

\section{Introduction}

The dorsal raphe (DR) modulates various aspects of physiology and behavior through serotonin [5-hydroxytryptamine (5-HT)]. The DR is divided into several subregions with distinct projection targets regulating anxiety, fear learning, reward and depression-like behaviors (Hioki et al., 2010; Hale and Lowry, 2011; Waselus et al., 2011; Qi et al., 2014; Natarajan et al., 2017; Ren et al., 2018; Huang et al., 2019). Serotonergic neurons in the dorsal region of the medial DR (DRD) and the ventral region of the medial DR (DRV) differentially project to the amygdala and cortical areas, and promote anxiety and active coping responses, respectively (Muzerelle et al., 2016; Ren et al., 2018). In turn, serotonergic neurons in the ventrolateral part of DR [DRVL 
(also called the lateral wing of DR)] innervate brain regions including the thalamus, superior colliculus (SC), periaqueductal gray, and hypothalamus (Muzerelle et al., 2016). The DRVL serotonergic and nonserotonergic neurons are activated by various types of stressors and have been suggested to regulate defensive behaviors (Johnson et al., 2008; Spiacci et al., 2012; Paul et al., 2014). Additionally, serotonergic neurons in the DR and the adjacent median raphe (MR) send abundant collateral projections to various rostral brain structures, including prefrontal cortex (PFC), septum, and hippocampus (HPC), that have also been implicated in anxiety and fear learning (Lacroix et al., 2000; Waselus et al., 2011; Muzerelle et al., 2016; Parfitt et al., 2017). The serotonergic neuron subtypes present unique molecular signatures (Okaty et al., 2015; Huang et al., 2019), but the mechanisms guiding their development remain incompletely understood.

The precursors of all DR and many MR serotonergic neurons are located in the embryonic $\mathrm{rV} 3$ (rhombencephalic V3) region and are derived from the rp 3 progenitors in the ventral rhombomere 1 (r1; Jensen et al., 2008; Haugas et al., 2016). After serotonergic progenitors become postmitotic, a specific cascade of transcription factors (TFs) is required to obtain their mature phenotype. One of the earliest genes expressed is Gata2. In the absence of Gata2, all serotonergic neurons fail to differentiate and progenitors give rise to ectopic Islet- $1^{+}, \mathrm{Slc17a6}^{+}$(VGluT2), and $\mathrm{Cart}^{+}$(cocaine- and amphetamine-regulated transcript protein) cells instead (Craven et al., 2004; Haugas et al., 2016). Downstream of GATA2, TFs LMX1B and PET1 are required for the terminal differentiation and maintenance of the serotonergic identity as they upregulate the expression of genes needed to synthesize and transport serotonin including Tph2 and Slc6a4 (Sert; Ding et al., 2003; Zhao et al., 2006; Liu et al., 2010; Song et al., 2011; Wyler et al., 2016). GATA3, another member of the GATA family, is required for the differentiation of Tph2 $2^{+}$and Slc6a4${ }^{+}$ neurons (Haugas et al., 2016). Unlike Gata2, the expression of Gata3 continues into adulthood and is important for the maintenance of serotonergic identity (Liu et al., 2010).

During the differentiation of several cell types, in particular in the hematopoietic system, GATA TFs interact with their zincfinger cofactor proteins ZFPM1 and ZFPM2 to repress or activate gene expression (Tsang et al., 1997; Fox et al., 1999; Lu et al., 1999; Tevosian et al., 2000; Robert et al., 2002; Pal et al., 2004; Beuling et al., 2008; Miccio et al., 2010; Chlon et al., 2012). During neuronal development, ZFPM2 was recently shown to be important for the full differentiation of corticothalamic projection neurons in developing cortex and GABAergic neuron subtypes in r1 (Galazo et al., 2016; Morello et al., 2020). The related cofactor ZFPM1 is also expressed in the DR serotonergic neuron precursors (Lahti et al., 2016), but the function of ZFPM1 in their differentiation is not understood.

Here, we analyzed the requirement of ZFPM1 for the development of r1-derived serotonergic and GABAergic neurons. We show that ZFPM1 is important for the normal development of $\mathrm{r} 1$ serotonergic neuron subtypes in the DRVL and DRD. Consequently, $Z f p m 1$ mutant mice display increased anxiety-like behavior and contextual fear memory, which can be alleviated by chronic fluoxetine (flx) treatment.

\section{Materials and Methods}

Mice

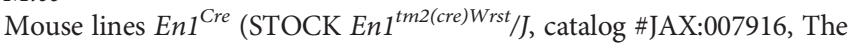
Jackson Laboratory; Kimmel et al., 2000), Zfpm flox (Katz et al., 2003), and Zfpm $2^{f l o x}\left(Z f p m 2^{\text {tm2Sho}} / E i J\right.$, catalog \#JAX:007266, The Jackson Laboratory; Manuylov et al., 2007), maintained on ICR background, were used to generate conditional $Z f p m 1^{C K O}\left(E n 1^{C r e /+} ; Z f p m 1^{f l o x / f l o x}\right)$ and compound $Z f p m 1$ and $Z f p m 2$ mutants $Z f p m 1^{\text {CKO }} ; Z f p m 2^{C K O}$ $\left(E n 1^{C r e /+} ; Z f p m 1^{\text {flox/flox }} ; Z f p m 2^{\text {flox/flox }}\right)$. Littermates were used as a control (ctrl) in both anatomic and behavioral studies of the $Z \mathrm{fpm} 1^{\text {cko }}$ mutant mice. The mouse cohorts are described below in the Experimental design and statistical analysis subsection. ICR animals were used for studies involving only wild-type mice. All animal experiments in this study were conducted with permission from the National Animal Experiment Board in Finland (ELLA; ESAVI/8132/04.10.07/2017).

\section{Histology}

Embryos [embryonic day 12.5 (E12.5)] or their brains (E18.5) were dissected in $1 \times$ PBS and fixed in $4 \%$ paraformaldehyde (PFA; catalog \#P6148, Sigma-Aldrich) for $2 \mathrm{~d}$. Adult animals (2 months old) were perfused intracardially with $4 \%$ PFA and postfixed for $2 \mathrm{~d}$ at room temperature (RT). Tissue was embedded into paraffin using an ASP500 Leica tissue processor, and $5-\mu \mathrm{m}$-thick paraffin sections were made. The sectioning planes, indicated in the figures, were controlled with anatomic landmarks (brainstem nuclei, shape of the ventricle and dorsal structures). The entire DR region was sectioned, and corresponding sections were used for further analyses.

\section{Immunohistochemistry}

For immunohistochemistry (IHC), paraffin sections were rehydrated using standard xylene and degrading ethanol (100\% to 50\%) series and were permeabilized with a $0.3 \%$ Triton X-100 (catalog \#T9284, SigmaAldrich) solution in $1 \times$ PBS for $10 \mathrm{~min}$. Antigens were retrieved by boiling in the microwave for $12 \mathrm{~min}$ with $0.1 \mathrm{M} \mathrm{Na}$-citrate buffer, $\mathrm{pH}$ 6.0. Slides were blocked with $10 \%$ donkey serum (catalog \#S2170, Biowest) in $0.1 \%$ Triton X-100 for $1 \mathrm{~h}$. Afterward, slides were incubated with primary antibody (diluted in the blocking solution) overnight at $4^{\circ} \mathrm{C}$. The next day, slides were incubated with the secondary antibodies for $4 \mathrm{~h}$ at RT and counterstained with DAPI $\left(4^{\prime}, 6^{\prime}\right.$-diamidino-2-phenylindole dihydrochloride; catalog \#D9564, Sigma-Aldrich). The following primary antibodies used in this study: rabbit anti-5-HT (1:500; catalog \#20 080, ImmunoStar; RRID:AB_572263); mouse anti-NKX2.2 [1:400; catalog \#74.5A5, Developmental Studies Hybridoma Bank (DSHB); RRID:AB_531794]; rabbit anti-ZFPM2 (1:200; catalog \#sc-10 755; Santa Cruz Biotechnology); mouse anti-GATA3 (1:200; catalog \#sc-268, Santa Cruz Biotechnology; RRID:AB_2108591); rabbit anti-GATA2 (1:200; catalog \#sc-9008, Santa Cruz Biotechnology; RRID:AB_2294456); mouse anti-HuC/D (1:200; catalog \#A-21 271, Thermo Fisher Scientific; RRID: AB_221448); rat anti-BCL11B (1:500; catalog \#ab18465, Abcam; RRID: AB_2064130); mouse anti-TH (1:1000; catalog \#MAB318, Millipore; RRID:AB_2201528); mouse anti-FOXP1 (1:500; catalog \#ab32010, Abcam; RRID:AB_1141518); and mouse anti-PAX7 (1:300; catalog \#AB_528428, DSHB; RRID:AB_528428). The following secondary antibodies were used in this study: donkey anti-rabbit IgG Alexa Fluor 568 (1:400; catalog \#A10042, Thermo Fisher Scientific; RRID:AB_2534017); donkey anti-rat IgG Alexa Fluor 488 (1:400; catalog \#A21208, Thermo Fisher Scientific; RRID:AB_2535794); donkey anti-rat IgG Alexa Fluor 568 (1:400; catalog \#AB175475, Thermo Fisher Scientific; RRID:AB_ 2636887); and donkey anti-mouse IgG Alexa Fluor 488 (1:400; catalog \#A-21 202, Thermo Fisher Scientific; RRID:AB_141607).

\section{$m R N A$ in situ hybridization}

For mRNA in situ hybridization (ISH), digoxigenin- or fluorescein-labeled cRNA probes were synthesized using RNA-labeling kits (catalog \#11277073910 and catalog \#11685619910, Roche). The following probes were used in this study: Slc17a8 (Guimera et al., 2006); Zfpm1 (IMAGE3585094, Source BioScience); Slc6a4 (RP_071204_04_G10 from Allen Brain Atlas; Lein et al., 2007); Gad1 (glutamic acid decarboxylase 1; Guimera et al., 2006); Sox14 (IMAGp998A2414391Q, Source BioScience); Sst (IMAGp998H231140Q, Source BioScience); Tph2 (RP_060220_03_C04 from Allen Brain Atlas; Lein et al., 2007); and Pet1 (clone UI-M-BH3-avj-b-02-0-UI.s1), Gata2, and Gata3 (Lilleväli et al., 2004). Paraffin slides were rehydrated and permeabilized, and antigens were retrieved as in the IHC protocol. After antigen retrieval, tissue was additionally permeabilized with $20 \%$ SDS in $1 \times$ PBS for $20 \mathrm{~min}$ and 
incubated with $0.25 \%$ acetic anhydride (catalog \#33214, Sigma-Aldrich) in $0.1 \mathrm{~m}$ triethanolamine (catalog \#33729, Sigma-Aldrich) for $10 \mathrm{~min}$. Next, slides were dehydrated using graded ethanol series (50\% to $100 \%$ ) and dried for $1 \mathrm{~h}$. Probes were diluted 1:400 in hybridization buffer [10\% dextran sulfate (catalog \#D8906, Sigma-Aldrich); $0.3 \mathrm{M} \mathrm{NaCl;} 20 \mathrm{~mm}$ Tris-HCl, pH 8.0; 5 mm EDTA, pH 8.0; $1 \times$ Denhardt's solution (catalog \#D2532, Sigma-Aldrich); 50\% formamide (catalog \#75-12-7, Millipore); $500 \mu \mathrm{g} / \mathrm{ml}$ yeast tRNA (catalog \#R6750, Sigma-Aldrich)] and incubated at $65^{\circ} \mathrm{C}$ overnight. Next day, slides were washed with $5 \times$ SSC (saline-sodium citrate buffer) and with $50 \%$ formamide in $2 \times \mathrm{SSC}$ at $65^{\circ} \mathrm{C}$ for $1 \mathrm{~h}$ in the water bath and afterward were treated with $0.02 \mathrm{mg} / \mathrm{ml}$ RNAseA (catalog \#10109169001, Roche) in NTE buffer (0.5 M NaCl; $5 \mathrm{~mm}$ Tris$\mathrm{HCl}, \mathrm{pH} 8.0 ; 5$ mm EDTA, $\mathrm{pH} 8.0$ ) at $37^{\circ} \mathrm{C}$ for $1 \mathrm{~h}$. Next, slides were washed with $50 \%$ formamide in $2 \times \mathrm{SSC}$ at $65^{\circ} \mathrm{C}$ for $1 \mathrm{~h}$ in the water bath and washed with $2 \times$ SSC and $0.1 \times$ SSC for $10 \mathrm{~min}$, and with $1 \times$ TBST [25 mм Tris-HCl, pH 7.5; 150 mм NaCl; 2.7 mм KCl; 0.1\% Tween-20 (catalog \#P7949, Sigma-Aldrich)] for $5 \mathrm{~min}$. Afterward, slides were blocked with TNB blocking buffer $[0.1 \mathrm{~m}$ Tris- $\mathrm{HCl}, \mathrm{pH} 7.5 ; 0.15 \mathrm{M} \mathrm{NaCl}$; $0.5 \%$ blocking reagent (catalog \#FP1012, PerkinElmer)] for $1 \mathrm{~h}$ and incubated with sheep anti-digoxigenin-POD (peroxidase) Fab fragments antibody (1:800; catalog \#11207733910, Roche) or sheep anti-fluorescein-POD Fab fragments (1:800; catalog \#11426346910, Roche) antibody at $+4^{\circ} \mathrm{C}$ overnight. Either the TSA Plus Cyanine 3.5 system (catalog \#NEL763B001KT, PerkinElmer) or the TSA Plus Fluorescein system (catalog \#NEL741B001KT, PerkinElmer) was used to detect the antibody. Afterward, IHC was conducted on the slides starting with the blocking step. For double ISH, two different probes (digoxigenin and fluorescein labeled) were incubated simultaneously. The fluorescein-labeled probe was first detected with the TSA Plus Fluorescein system and the peroxidase activity was quenched with $0.2 \mathrm{~N} \mathrm{HCl}$ for $40 \mathrm{~min}$, after which the slides were incubated with sheep anti-digoxigenin-POD Fab fragments antibody at $+4^{\circ} \mathrm{C}$ overnight and visualized with TSA Plus Cyanine 3.5 kit.

\section{Behavioral tests}

Forced swim test. Animals were put into cylindrical glass beakers (height, $265 \mathrm{~mm}$; diameter, $170 \mathrm{~mm}$ ) containing $150 \mathrm{~mm}$ of water $\left(\sim 25^{\circ} \mathrm{C}\right)$ and their swimming behavior was recorded for $6 \mathrm{~min}$. After the experiment, the mice were placed into the new cage to dry and soon were returned to their home cage. The recordings were analyzed, and their time spent immobile (a mouse was considered to be immobile when it only made infrequent hindlimb movements to stay afloat) was measured by the person blinded to the genotype in the last $4 \mathrm{~min}$ of the recorded session.

Novel object recognition. Animals were acclimated in a transparent wall square arena (side, $30 \mathrm{~cm}$; height, $20 \mathrm{~cm}$ ) without any object for $15 \mathrm{~min}, 2 \mathrm{~d}$ before the test session. In the pretest session ( $24 \mathrm{~h}$ before test), the animals were presented to two identical objects (A) for $15 \mathrm{~min}$. For the test session, one of the objects was substituted (object B), and an observer blind to the genotype determined the number of interactions with each object in the 5 min session (Ampuero et al., 2013).

Elevated plus maze. The animals were acclimated in the room for $1 \mathrm{~h}$ before the test in the elevated plus maze $(E P M$; walls: length, $30 \mathrm{~cm}$; width, $5 \mathrm{~cm}$; height, $15 \mathrm{~cm}$ high). For the test session, animals were placed in the center of the apparatus (elevated $50 \mathrm{~cm}$ above ground), and the software (EthoVision XT version 13, Noldus) determined the number of entries in the open and enclosed arms (Carobrez and Bertoglio, 2005).

Contextual fear conditioning. The contextual fear conditioning (CFC) was conducted in a transparent acrylic cage $(23 \times 23 \times 35 \mathrm{~cm}$, with constant light at $100 \mathrm{lux})$. The mice were conditioned to five scrambled footshocks $(0.6 \mathrm{~mA} / 2 \mathrm{~s})$ during the total $13 \mathrm{~min}$ session. The total activity was recorded in the first $5 \mathrm{~min}$ of the session, where no shock was delivered. During the extinction trials $(24,48$, and $72 \mathrm{~h}$ after the conditioning), the animals were exposed to the same context where the shocks were delivered, and the time spent in freezing during the $8 \mathrm{~min}$ session was automatically determined by the software (TSE Systems). An independent cohort of animals received fluoxetine for 3 weeks and was submitted to the CFC as described previously. One week after the last extinction session (ext 3), the animals were submitted to another shock [fear reinstatement (FR)] and one extinction session (24 h after fear reinstatement).

Contextual discrimination. This task was conducted in the same apparatus as CFC. The animals were exposed to context A (grid floor with transparent walls $23 \times 23 \times 35 \mathrm{~cm}$ for $10 \mathrm{~min}$ ), and $24 \mathrm{~h}$ later they were exposed to context B (same dimensions, black acrylic floor and walls). The animals were then exposed to context A ( $24 \mathrm{~h}$ after the exposure to context B). In all three sessions, no shock was delivered and the software calculated the distance traveled.

\section{High-performance liquid chromatography}

5-HT, dopamine, 3,4-dihydroxyphenylacetic acid (DOPAC), homovanillic acid (HVA), and noradrenaline tissue concentration analysis was conducted as described previously, with small modifications (Airavaara et al., 2006). Briefly, weighed frozen samples were sonicated in $500 \mu \mathrm{l}$ of homogenization solution consisting of $0.2 \mathrm{M} \mathrm{HClO}_{4}$ and antioxidant solution containing oxalic acid with acetic acid and L-cysteine (Kankaanpää et al., 2001) until no large pieces of tissue were visible in the tube. Samples were kept on ice and then centrifuged at $+4^{\circ} \mathrm{C}$ and $14,000 \mathrm{rpm}$ for $35 \mathrm{~min}$. Then, $300 \mu \mathrm{l}$ of supernatant was transferred to $500 \mu \mathrm{l}$ Vivaspin filter tubes and centrifuged at $+4^{\circ} \mathrm{C}$ and $9000 \mathrm{rpm}$ for $35 \mathrm{~min}$. Next, $75 \mu \mathrm{l}$ of sample was then transferred to high-performance liquid chromatography (HPLC) vials. The column $(2.6 \mu \mathrm{m}, 4.6 \times 100$ $\mathrm{mm} \mathrm{C}-18$; Kinetex, Phenomenex) was kept at $45^{\circ} \mathrm{C}$ with a column heater (CROCO-CIL). The mobile phase consisted of $0.1 \mathrm{M} \mathrm{NaH}_{2} \mathrm{PO}_{4}$ buffer, $220 \mathrm{mg} / \mathrm{L}$ octane sulfonic acid, methanol (8\%), and $450 \mathrm{mg} / \mathrm{L}$ EDTA, and the $\mathrm{pH}$ was set to four using $\mathrm{H}_{3} \mathrm{PO}_{4}$. A pump (model 582 Solvent Delivery Module, ESA) equipped with two pulse dampers (SSI LP-21, Scientific Systems) provided a $1 \mathrm{ml} / \mathrm{min}$ flow rate. Fifty microliters of the sample were injected into the chromatographic system with a Shimadzu SIL-20AC autoinjector. Analytes were detected using an ESA CoulArray Electrode Array Detector, and chromatograms were processed and concentrations of monoamines calculated using CoulArray software (ESA). Values were calculated in nanograms per gram of wet tissue.

\section{5-HT fiber staining, image acquisition and quantification}

Two-month-old Zfpmi ${ }^{C K O}$ and ICR mice were used to analyze 5-HT innervation. Animals were perfused, $40-\mu \mathrm{m}$-thick coronal sections were cut using a vibratome (model VT1200S, Leica), and sections were stored in ice-cold $1 \times$ PBS until further processing. Tissue sections were permeabilized with $0.3 \%$ Triton X-100 (catalog \#T9284, Sigma-Aldrich) solution in $1 \times$ PBS for $45 \mathrm{~min}$ at RT and subsequently blocked with $10 \%$ donkey serum (catalog \#S2170, Biowest) prepared in 0.3\% Triton X-100 for $2 \mathrm{~h}$ at RT. Tissue sections were incubated for $48 \mathrm{~h}$ at $+4^{\circ} \mathrm{C}$ with rabbit anti-5-HT primary antibody (1:300; catalog \#20080, ImmunoStar; RRID:AB_572263) diluted in the 5\% donkey serum prepared using $0.25 \%$ Triton X-100. Finally, the sections were incubated with donkey anti-rabbit IgG Alexa Fluor 488 secondary antibody (catalog \#A-21206, Thermo Fisher Scientific; RRID:AB_2535792; 1:300) overnight at $+4^{\circ} \mathrm{C}$.

Confocal images of 5-HT fibers were obtained using a Leica SP8 STED microscope with $93 \times$ glycerol-immersed objective using argon laser $(488 \mathrm{~nm})$ at an exposure of $5 \mu \mathrm{s} /$ pixel, a numerical zoom of 1.50, and a $z$-step of $0.3 \mu \mathrm{m}$. Approximately $65 z$-stack images per section were acquired at a resolution of $1024 \times 1024$ pixels. To quantify 5-HT fiber density, we followed the previously described procedure (Kiyasova et al., 2011) using ImageJ software. In brief, the procedure included conversion of confocal images to an 8 bit RGB format, background subtraction using roller-ball method, normalization, extraction of binary image, and measurement of positive and negative areas by applying fixed threshold levels.

\section{Experimental design and statistical analysis}

For the behavioral experiments five mouse cohorts were bred. Cohort 1 contained 2-month-old female and male control (4 males, 10 females) and $Z f p m 1^{C K O}$ ( 6 males, 7 females) animals that were used in the novel object recognition (NOR), EPM, and CFC, in this sequence, with a 5-7 d interval between each behavioral test. Afterward, PFC, HPC, and dorsal midbrain $(\mathrm{dMB})$ were dissected from females and used in HPLC 
analysis. Cohort 2 contained 6- to 8-monthold female control $(N=11)$ and $Z f p m 1^{C K O}$ $(N=6)$ animals that were used for the contextual memory experiment. Cohorts 3 and 4 contained 3- to 6-month-old female control and $Z f p m 1^{C K O}$ animals that were divided into the following two groups: fluoxetinetreated group (Cohort 3: control, $N=8$; $Z f p m 1^{C K O}, N=7$; Cohort 4: control, $N=8$; $\left.Z f p m 1^{C K O}, N=8\right)$; and water-treated control group (Cohort 3: control, $N=8 ; Z f p m 1^{C K O}$, $N=4$; Cohort 4: control, $N=8 ; Z f p m 1^{C K O}$, $N=8$ ). Both Cohort 3 and 4 animals were used in the CFC and subsequent fear reinstatement. Cohort 5 included 5- to 8-monthold male control and $Z f p m 1^{C K O}$ animals that received acute administration of fluoxetine (15 mg/kg; control, $\left.N=7 ; Z f p m 1^{C K O}, N=9\right)$ or PBS (control, $N=10 ; Z f p m 1^{C K O}, N=10$ ), and a forced swim test (FST) was conducted.

The statistical analysis was done using GraphPad Prism 7.00 and IBM SPSS Statistics versions 24 and 25 . When comparing two sets of measurements, the presence of significant outliers in the data was assessed using boxplots, while distribution was evaluated using the Shapiro-Wilk test for normality, where $p>0.05$ was considered normally distributed. An independent-samples $t$ test (two tailed) was used when outliers were absent and data were normally distributed, and a Levene's test of equality of variances was conducted to determine the equal variances in each group $(p>0.05$ homogeneity of variances was assumed). Otherwise, an independent-samples Mann-Whitney $U$ test (two tailed) was conducted. Data are presented as the mean with SD or SEM. Welch's one-way ANOVA with Games-Howell post hoc test was used to compare three sets of measurements. Two-way ANOVA was used to analyze the effect of genotype (control/ $Z f p m 1^{C K O}$ ) on the variable in the males and females (or PBS/fluoxetine-treated animals) and was followed up with the multiple-comparison Fisher's least significant difference (LSD) post hoc test. The contextual memory and CFC data were analyzed with two-way repeated-measures ANOVA with Fisher's LSD post hoc test where sphericity was assumed $\left({ }^{*} p<0.05,{ }^{* *} p<0.01,{ }^{* * *} p<\right.$ $\left.0.001,{ }^{* * * *} p<0.0001\right)$.

\section{Results}

$Z f p m 1$ is expressed in the postmitotic serotonergic and GABAergic precursors in the $\mathbf{r} 1$

A previous study demonstrated ZFPM1 in the ventral $\mathrm{r} 1$, where its expression in putative serotonergic precursors was GATA2 dependent (Lahti et al., 2016). We analyzed the expression of $Z f p m 1$ in more detail in the ventral $\mathrm{r} 1$ from E10.5 to E12.5, when the serotonergic neurons are exiting the cell cycle (Haugas et al., 2016). Already at E10.5, we detected Zfpm1 transcripts in the $\mathrm{rV} 3$ domain
A

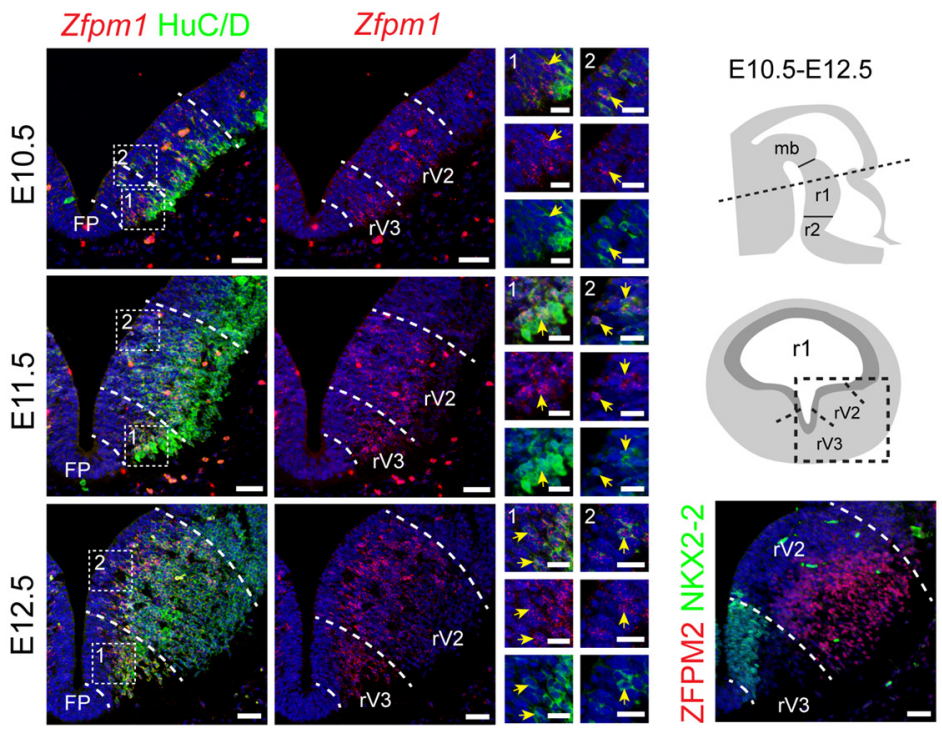

B
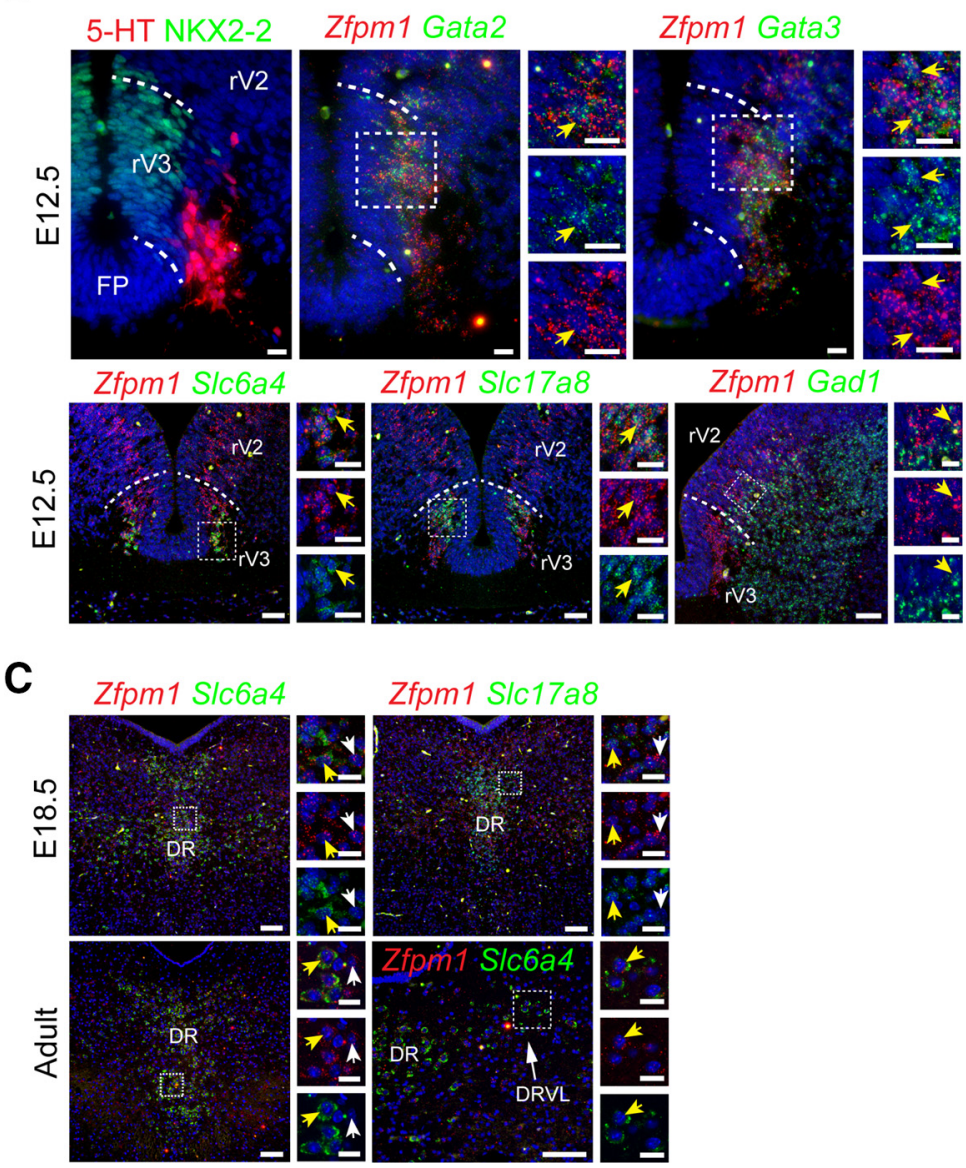

Figure 1. Zfpm 1 is expressed in the serotonergic and GABAergic neurons from E10.5 to adult. $\boldsymbol{A}$, Expression of Zfpm 1 in postmitotic cells in the rV3 and rV2 domains of $r 1$ from E10.5 to 12.5. Left, Transversal sections of $r 1$ showing the expression of Zfpm1 (ISH) and the postmitotic marker HuC/D (IHC). Right, Expression of ZFPM2 and NKX2-2 (IHC) in the rV2. Yellow arrows mark coexpression. Scale bars: $50 \mu \mathrm{m}$; close-up, $20 \mu \mathrm{m}$. FP, Floor plate. $\boldsymbol{B}$, Expression of Zfpm1 in the serotonergic and GABAergic neurons at E12.5. Top, Parallel sections analyzed for the expression of 5-HT and NKX2-2 (IHC), Zfpm1 and Gata2 (double ISH), and Zfpm1 and Gata3 (double ISH) in the serotonergic rV3 domain. Bottom, Expression of Zfpm1 together with serotonergic markers SIC6a4 and S/c17a8 as well as a GABAergic marker Gad1 (double ISH) at E12.5. Yellow arrows mark coexpression. Scale bars: $50 \mu \mathrm{m}$; close-up, $20 \mu \mathrm{m}$. C, Expression of Zfpm1 with S/c17a8 and SIC6a4 (double ISH) in DR at E18.5 and adult. Yellow arrows mark coexpression, white arrows indicate single positive cells. Scale bars: $100 \mu \mathrm{m}$; close-up, $20 \mu \mathrm{m}$. 
A
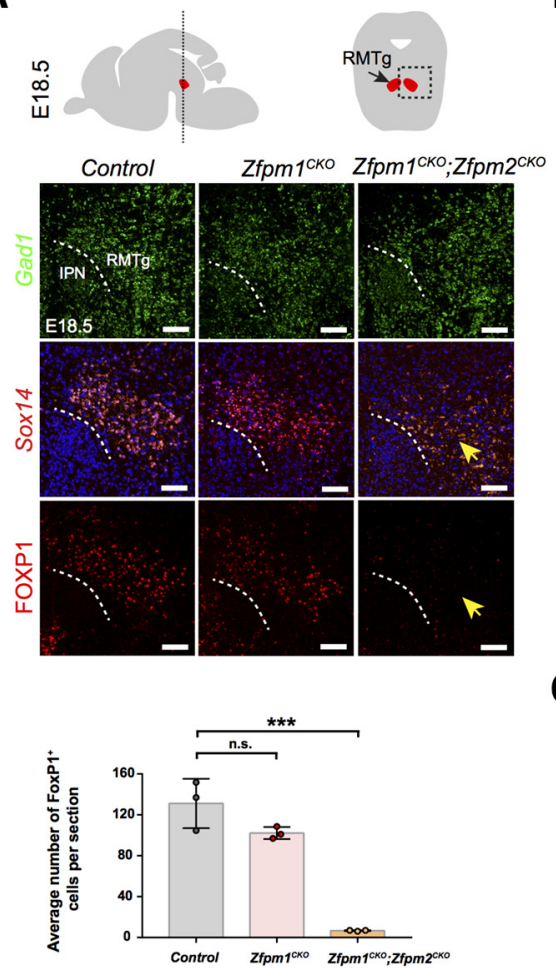

D
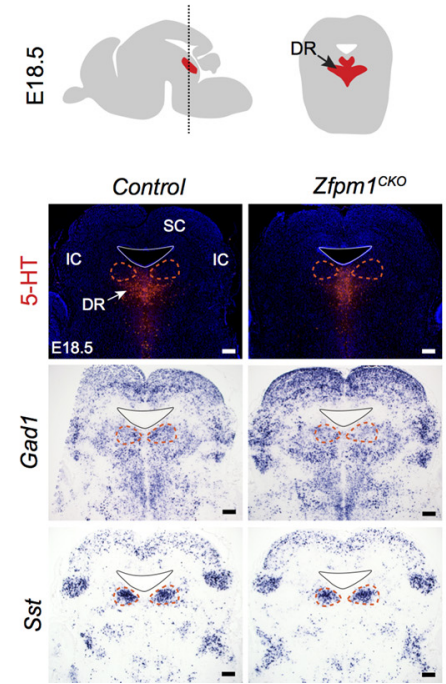

B
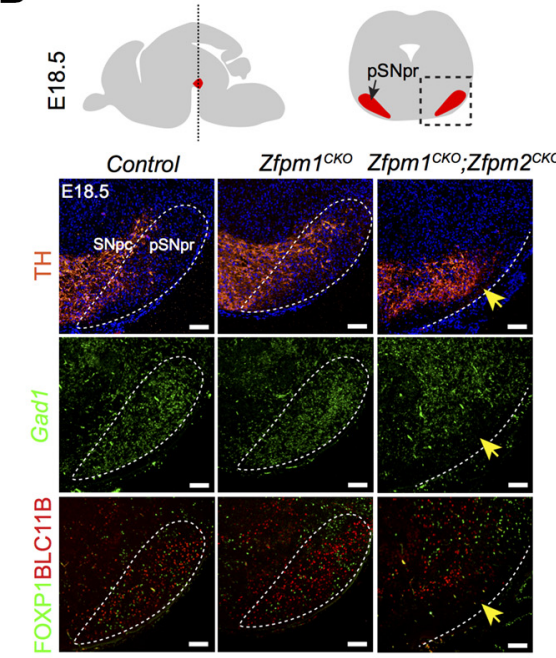

C
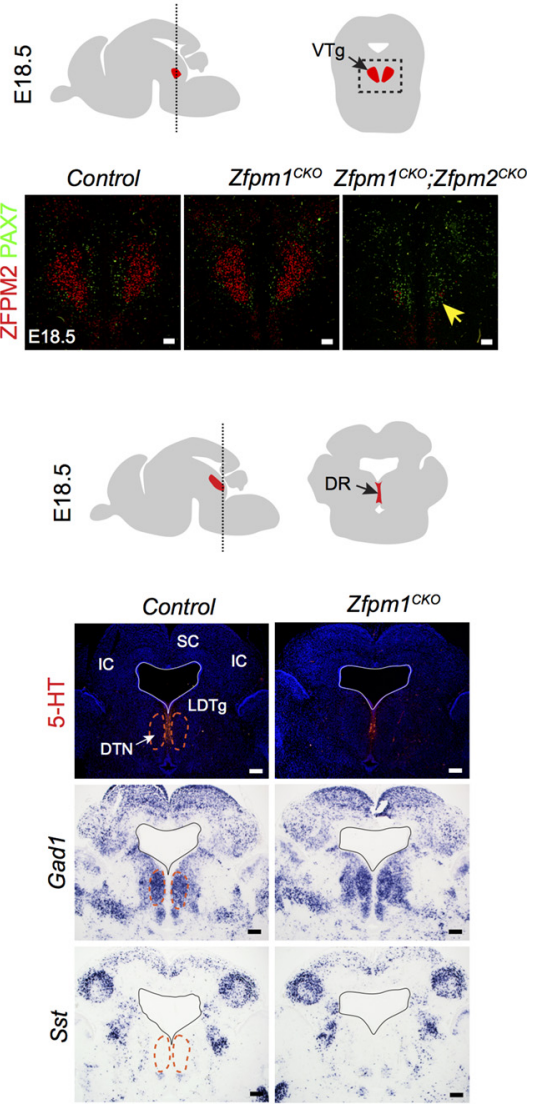

Figure 2. Development of GABAergic neurons in the RMTg, SNpr, VTg, and DR in Zfpm $1^{C_{K} \mathrm{KO}}$ and Zfpm $1^{\mathrm{CKO}} ; \mathrm{Zfpm} 2^{\mathrm{CKO}}$ mice. A, FOXP1 (IHC), Sox14, and Gad1 (ISH) expression in the RMTg of Zfpm1 $1^{C K O}$ and $Z f p m 1^{C K O} ; Z f p m 2^{C K O}$ embryos at E18.5. Yellow arrows indicate a decrease of Sox $14^{+}$and FoxP1 ${ }^{+}$neurons. Quantification of Fox ${ }^{+}$cells in the RMTg: $N=3$ embryos/genotype, positive cells were counted per section (five sections per animal), and the average cell number was calculated per animal. Data are visualized as the mean with the SD. Welch's ANOVA showing significant decrease of FoxP1 ${ }^{+}$cells between different genotypes (Welch's $F_{(2,2.684)}=345.07, p<0.001$ ). Multiple comparison (Games-Howell post hoc test) showed a lower amount of FoxP1 ${ }^{+}$cells in Zfpm ${ }^{C K O}$; Zfpm $2^{\text {CKO }}$ embryos compared with control embryos $(p=0.022)$, but not in Zfpm $1^{\text {CKO }}$ embryos $(p=0.293)$. Scale bars, $100 \mu \mathrm{m}$. IPN, Interpeduncular nucleus. $\boldsymbol{B}$, TH, FOXP1, BCL11B (IHC), and Gad1 (ISH) expression in the pSNpr of Zfpm $1^{C K O}$ and $Z f p m 1^{C K O} ; Z f p m 2^{C K O}$ animals at E18.5. Yellow arrows indicate the loss of pSNpr neurons in the double mutants. Scale bars, $100 \mu \mathrm{m}$. SNpc, Substantia nigra pars compacta. C, ZFPM2 and PAX7 (IHC) expression in the VTg of Zfpm $1^{C K O}$ and $Z f p m 1^{C K O} ; Z f p m 2^{C K O}$ embryos at E18.5. Yellow arrow indicates the decrease of VTg neurons in the double mutants. Scale bars, $50 \mu \mathrm{m}$. D, Gad1 and Sst expression near DR (marked with 5-HT) in control and Zfpm $1^{\mathrm{CKO}}$ embryos at E18.5. Scale bars, $200 \mu \mathrm{m}$. DTN, Dorsal tegmental nucleus; LDTg, laterodorsal tegmental nucleus; IC, inferior colliculus. ${ }^{* *} p<0.001$, n.s. not significant.

giving rise to serotonergic precursors, and this expression was maintained at E11.5 and E12.5 (Fig. 1A). Zfpm1 was also expressed in the rV2 domain that generates GABAergic and glutamatergic neurons (Fig. 1A; Lahti et al., 2016). A related GATA cofactor, ZFPM2, was also detected in the rV2, but not in the serotonergic rV3 domain (Fig. 1A). Zfpm1 expression colocalized with a postmitotic marker, HuC/D (Okano and Darnell, 1997), indicating that $Z f p m 1$ is activated in the precursors after they have exited the cell cycle (Fig. 1A). Similarly, GATA2 and GATA3 are expressed postmitotically in the serotonergic precursors from E10.5 onward (Haugas et al., 2016), and Zfpm1 transcripts colocalized with both Gata2 and Gata3 in the rV3 domain from E10.5 to E12.5 (Fig. 1B; data not shown). To demonstrate the cell-type specificity, we analyzed $Z f p m 1$ expression together with serotonergic and GABAergic markers. At E12.5, the rV3 domain contains two distinct serotonergic precursor populations, a dorsally positioned $\mathrm{Slc} 17 a 8^{+}$and a ventrally located Slc6a4 ${ }^{+}$population (Haugas et al., 2016). We detected Zfpm1 expression in both of these serotonergic precursor populations (Fig. 1B). In addition, we found $Z f p m 1$ transcripts in the $\mathrm{rV} 2$ GABAergic precursors, marked by Gad1. In E18.5 and adult DR, Zfpm 1 expression was maintained in both Slc6a4 ${ }^{+}$and Slc17a8 ${ }^{+}$serotonergic neurons (Fig. 1C). These results demonstrate that the GATA cofactor $Z f p m 1$ is expressed in the early postmitotic serotonergic precursors, similar to GATA2 and GATA3 (Haugas et al., 2016), and that its expression is maintained in the mature serotonergic neurons, similar to GATA3 and PET1 (Liu et al., 2010).

Zfpm1 is not required for the development of the r1-derived posterior substantia nigra pars reticulata, rostromedial tegmental nucleus, and ventral tegmental nucleus of Gudden GABAergic neurons

In addition to the serotonergic precursors, $Z f p m 1$ was expressed by the GABAergic precursors in the rV2 domain. These precursors contribute to multiple GABAergic nuclei in the ventral midbrain and anterior hindbrain, including the posterior substantia nigra pars reticulata (pSNpr), rostromedial tegmental nucleus (RMTg) and the ventral tegmental nucleus of Gudden (VTg; Achim et al., 2012; Lahti et al., 2016; Morello et al., 2020). In addition to Zfpm1, the GABAergic precursors in the rV2 also express ZFPM2 (Fig. 1A), 
A
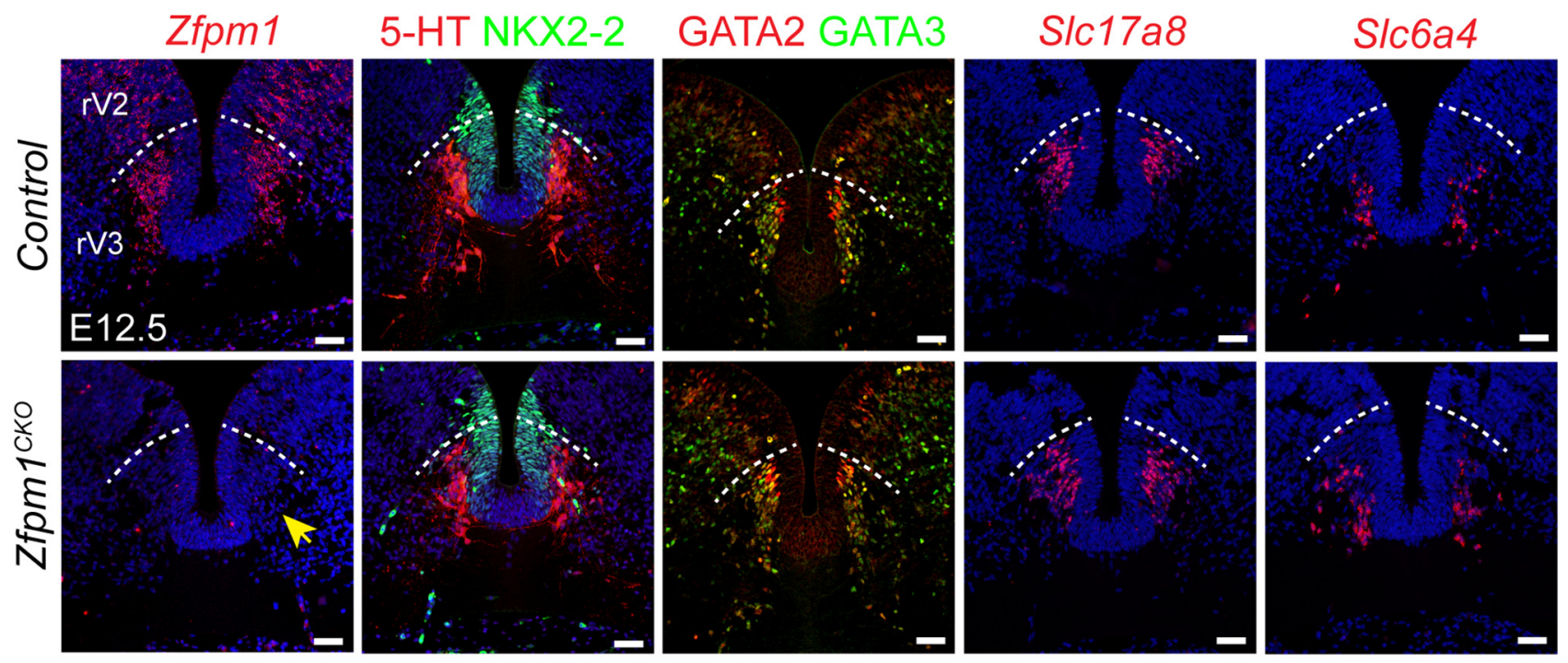

B

5-HT

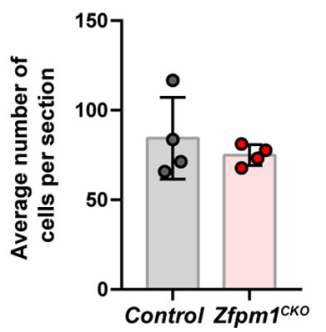

SIc17a8

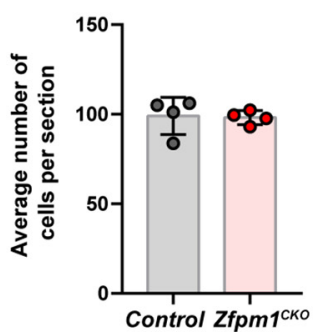

SIc6a4

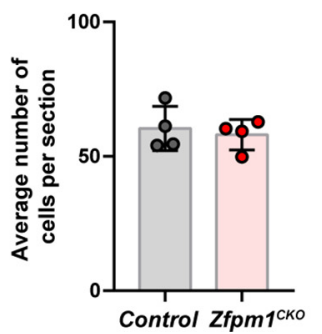

Figure 3. Early differentiation of $\mathrm{r} 1$ serotonergic neurons is not affected in Zfpm $7^{\mathrm{CKO}}$ embryos. A, Expression of Zfpm1 (ISH); 5-HT, NKX2-2, GATA2, and GATA3 (IHC); and S/c17a8 and S/c6a4 (ISH) in the $\mathrm{r} 1$ of control and Zfpm $7^{\mathrm{CKO}}$ embryos at E12.5. Yellow arrow indicates the loss of Zfpm1 expression in the Zfpm $7^{\text {CKO }}$. Scale bars, $50 \mu \mathrm{mm}$. B, The amount of 5-HT, Slc17a8 ${ }^{+}$, and $S / c 6 a 4^{+}$cells has not changed in the Zfpm $7^{C K O}$ compared with the control embryos. $N=4$ embryos/genotype-positive cells were counted per section (six sections per animal), and the average cell number was calculated per animal. Data are visualized as the mean with the SD (5-HT: $t_{(6)}=0.801, p=0.453 ;$ SIc17a8: $t_{(6)}=0.165, p=0.874 ;$ Slc6a4: $t_{(6)}=0.450, p=0.669 ;$ independent-samples two-tailed $t$ test). mb, Midbrain.

GATA2, GATA3, and TAL1 (T-cell acute lymphocytic leukemia protein 1), all required for the correct development of the $\mathrm{pSNpr}$, RMTg, and VTg GABAergic neurons.

Zfpm1-null mutant mouse embryos die at E10.5 to E12.5 because of severe anemia (Tsang et al., 1998). Similarly, inactivation of Zfpm 2 causes embryonic lethality between E13.5 and E15.5 as a result of heart defects (Tevosian et al., 2000). We overcame the early lethality of $Z f p m 1$ mutant embryos by generating En1 ${ }^{\text {Cre/+ }} ; Z f p m 1^{\text {flox/flox }}\left(Z f p m 1^{C K O}\right)$ mice, where $Z f p m 1$ is tissuespecifically inactivated in the midbrain-rl region before the onset of embryonic neurogenesis. In addition, we generated $\mathrm{EnI}^{\mathrm{Cre} /+}$; $Z f p m 1^{\text {flox/flox }} ; Z f p m 2^{\text {flox/flox }}\left(Z f p m 1^{C K O} ; Z f p m 2^{C K O}\right)$ mice, where both $Z f p m 1$ and $Z f p m 2$ were similarly inactivated. In both of these mutants, we detected no $Z f p m 1$ or $Z f p m 2$ expression in the rV2 and rV3 domains at E12.5 (see Fig. 3A; data not shown). Similar to the $Z f p m 2^{C K O}$ embryos (Morello et al., 2020), the early production of $\mathrm{rV} 2$-derived GABAergic precursors was unaffected in $Z f p m 1^{C K O}$ mutants at E12.5 (data not shown). In contrast to the $Z f p m 2^{C K O}$ and $Z f p m 1^{C K O} ; Z f p m 2^{C K O}$ mice, the pSNpr, RMTg, and VTg GABAergic neurons were present in the correct location and expressed their specific markers in $Z \mathrm{fpm} 1^{\mathrm{CKO}}$ mutants at E18.5 (Fig. 2A-C).

In addition to these GABAergic populations, the rV2 domain also generates other GABAergic neurons that reside in different regions of the anterior hindbrain including the DR (Huang et al., 2019). We investigated the requirement for $Z f p m 1$ in the development of GABAergic neurons near the DR by analyzing E18.5 $\mathrm{Zfpm} 1^{\text {CKO }}$ mutant mice for the expression of Gad1 and a GABAergic neuron subtype marker Sst (Huang et al., 2019). Compared with the control, we did not find differences in Gad1 or Sst expression in the Zfpm $1^{C K O}$ mutants (Fig. 2D).

These results implicate that, unlike ZFPM2, ZFPM1 is not required for the development of $\mathrm{rV} 2$-derived GABAergic neurons in the pSNpr, RMTg, VTg, and in the DR region. Midbrain GABAergic neurogenesis also appeared normal in the Zfpm $1^{\text {CKO }}$ mutants (data not shown). Thus, although we cannot exclude defects in subtypes of GABAergic neurons present in low numbers, our results suggest that GABAergic neuron development is largely unaffected in the $Z f p m 1^{C K O}$ mice.

\section{$Z f p m 1$ is not required for the early generation of} serotonergic neuron precursors in the $r 1$

Next, we asked whether ZFPM1 is required for the early production of serotonergic precursors in the embryonic r1. At E12.5, the expression of 5-HT, NKX2-2, GATA2, GATA3, Slc17a8, and Slc6a4 remained unchanged in serotonergic precursors of the $Z f p m 1^{C K O}$ embryos (Fig. $3 A$ ). Furthermore, quantification of 5$\mathrm{HT}^{+}$, Slc17a8 ${ }^{+}$, and Slc6a $4^{+}$cells in the $Z f p m 1^{C K O}$ and control embryos did not reveal any differences between the genotypes [5-HT: $t_{(6)}=0.801, p=0.453$; Slc17a8: $t_{(6)}=0.165, p=0.874$; Slc6a4: $t_{(6)}=0.450, p=0.669$ (independent-samples two-tailed $t$ test; Fig. 3B). This suggests that, unlike in the Gata2 and Gata3 
A
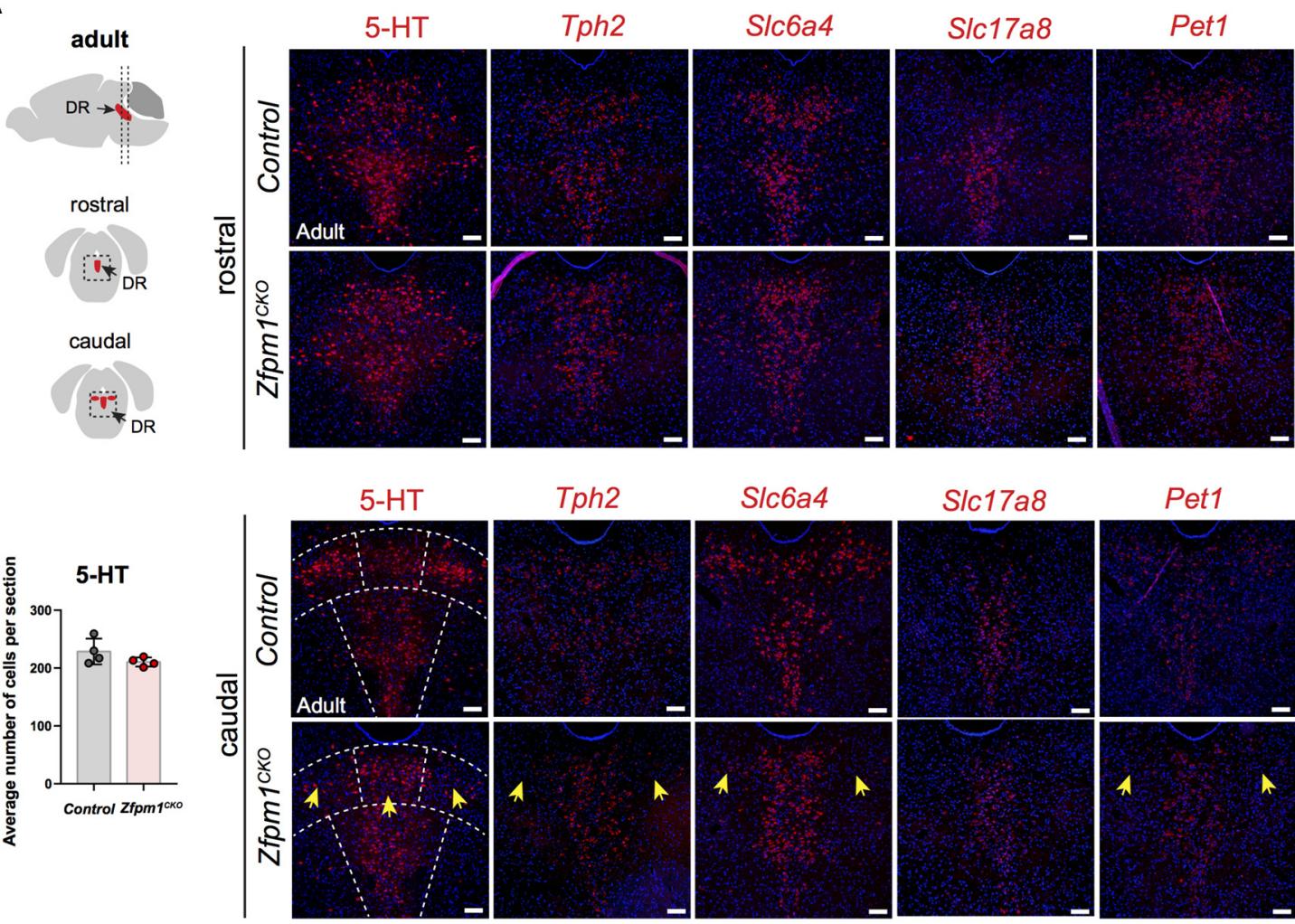

B

DRVL

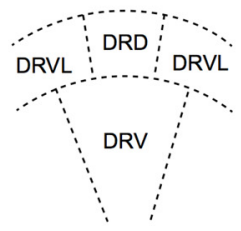

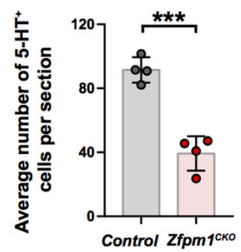

DRD

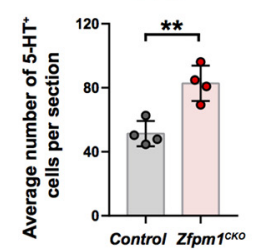

C

DRV

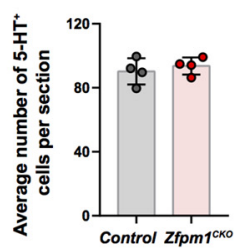

B8

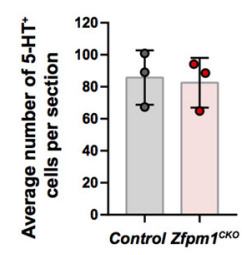

D
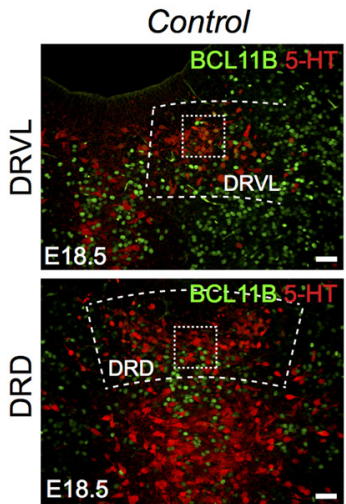

Zfpm $1^{\text {ско }}$

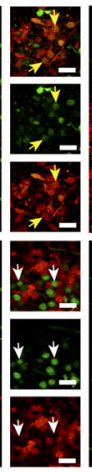

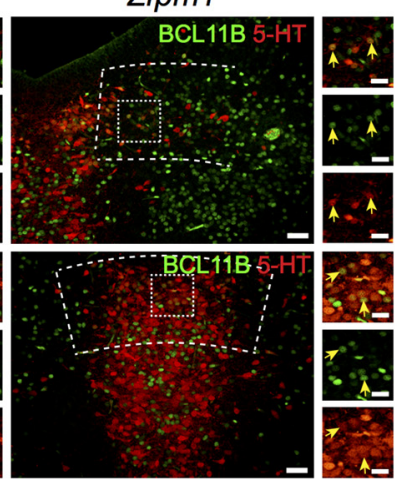
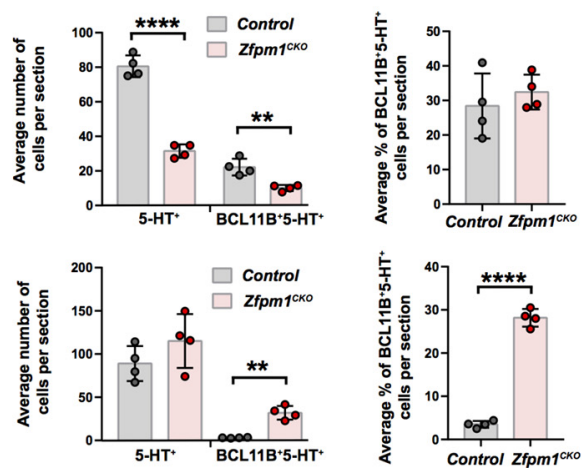

Figure 4. DRVL serotonergic neurons are reduced in Zfpm $7^{\mathrm{CKO}}$ mice. $\boldsymbol{A}$, Expression of 5-HT (IHC), and Tph2, Slc6a4, Slc17a8, and Pet7 (ISH) showing serotonergic neurons in the rostral and caudal DR in adult control and Zfpm $7^{C K O}$ mice. Yellow arrows show the change of cell distribution in the lateral and medial parts of the DR. Scale bars, $100 \mu \mathrm{m}$. Quantification of 5-HT ${ }^{+}$cells in the adult control and $Z \mathrm{fpm} 7^{\mathrm{CKO}}$ mice. $N=4$ embryos/genotype-positive cells (one genotype includes two females and two males) were counted per section from rostral to caudal DR (14 sections per animal), and the average cell number was calculated per animal. Data are visualized as a mean with the SD (independent-samples two-tailed $t$ test, $\left.t_{(6)}=1.531, p=0.177\right)$. $\boldsymbol{B}$, Scheme showing subregions of adult DR. Quantification of $5-\mathrm{HT}^{+}$cells in the different regions (DRVL, DRD, and DRV) of adult DR in the control and Zfpm $7^{\mathrm{CKO}}$ mice. $\mathrm{N}=4$ embryos/genotypepositive cells (one genotype includes two females and two males) were counted per section (six sections per animal), and the average cell number was calculated per animal. Data are visualized as the mean with the SD (independent-samples two-tailed $t$ test: DRD: $t_{(6)}=-4.623, p=0.004$; DRV: $t_{(6)}=-0.690, p=0.516$; DRVL: $t_{(6)}=7.822, p=0.0002$. C, Quantification of $5-\mathrm{HT}^{+}$cells in $\mathrm{B} 8$ (median raphe and prepontine raphe nucleus) of control and Zfpm $7^{\mathrm{CKO}}$ animals at E18.5. $\mathrm{N}=3$ embryos/genotype-positive cells were counted per section (six sections per ani$\mathrm{mal}$ ), and the average cell number was calculated per animal. Data are visualized as the mean with the SD (independent-samples two-tailed $t$ test, $t_{(4)}=0.2421, p=0.8206$ ). $\boldsymbol{D}, \mathrm{BCL} 11 \mathrm{~B}$ and 5-HT (IHC) expression in the DRD and DRVL in control and Zfpm $7^{\mathrm{CKO}}$ mice at E18.5. Yellow arrows indicate colocalization, white arrows show single positive cells. Scale bars: $50 \mu \mathrm{m}$; close-up, $20 \mu \mathrm{m}$. Quantification of 5- $\mathrm{HT}^{+}$and $\mathrm{BCL}_{11 \mathrm{~B}}{ }^{+} \mathrm{HT}^{+}$double-positive cells and percentage of $\mathrm{BCL}_{11 \mathrm{~B}^{+}} 5-\mathrm{HT}^{+}$double-positive cells from total $5-\mathrm{HT}^{+}$cells in the DRD and DRVL in control and 
mutant embryos (Haugas et al., 2016), the early serotonergic neurogenesis is not affected by the loss of $Z f p m 1$. Thus, although $Z f p m 1$ and GATA factors are coexpressed in the early serotonergic precursors (Fig. 1B), GATA2 and GATA3 seem to work independent of ZFPM1 to determine the serotonergic identity of the rV3 precursors.

\section{Zfpm1 regulates development of the DRVL serotonergic neurons in the DR}

To study whether ZFPM1 is required for later aspects of serotonergic neuron development, we analyzed the DR in perinatal and adult $Z f p m 1^{C K O}$ animals. Analysis of 5-HT, Tph2, Slc6a4, Slc17a8, and Pet1 expression in the rostral and caudal DR in adult $Z f p m 1^{C K O}$ mice revealed a loss of the serotonergic markers in the DRVL area of the caudal DR (Fig. 4A). However, quantification of the $5-\mathrm{HT}^{+}$DR neurons in the adult $Z f p m 1^{\mathrm{CKO}}$ and control mice did not show a difference between the genotypes $\left(t_{(6)}=1.531, p=0.177\right.$; independent-samples two-tailed $t$ test). Therefore, we divided the DR into dorsal (DRD), ventral (DRV), and ventrolateral (DRVL) parts and quantified the $5-\mathrm{HT}^{+}$neurons in each region in adult control and $Z f p m 1^{C K O}$ mice (Fig. $4 B)$. We detected a reduced number of $5-\mathrm{HT}^{+}$neurons in the DRVL area of the $Z f p m 1^{C K O}$ mice $\left(t_{(6)}=7.822, p=0.0002\right.$; independent-samples two-tailed $t$ test). In contrast, the number of 5 $\mathrm{HT}^{+}$cells had increased in the DRD area of the $Z \mathrm{fpm} 1^{\mathrm{CKO}}$ mice $\left(t_{(6)}=-4.623, p=0.004\right.$; independent-samples two-tailed $t$ test), while the $5-\mathrm{HT}^{+}$cell number remained comparable in the DRV region $\left(t_{(6)}=-0.690, p=0.516\right.$; independent-samples two-tailed $t$ test; Fig. $4 B$ ). No difference in $5-\mathrm{HT}^{+}$cell numbers between control and $Z \mathrm{fpm} 1^{\mathrm{CKO}}$ mice were detected in the B8 cell group containing the MR neurons $\left(t_{(4)}=0.2421, p=0.8206\right.$, independent-samples two-tailed $t$ test; Fig. $4 C$ ). These results suggest a change in the distribution of the serotonergic neurons in the adult DR from a lateral (DRVL) to a more medial (DRD) position in the absence of $Z f p m 1$. This phenotype could be caused by either a failure of differentiation of the DRVL serotonergic neurons, while the medial DRD serotonergic neurons are overproduced, or incorrect migration/positioning of the DRVL serotonergic neurons in the DR.

To study whether the positioning of the DRVL serotonergic neurons was altered in the $Z f p m 1^{C K O}$ mice, we set out to analyze the expression of DRVL-specific markers in the DR. The adult DR contains at least five different subtypes of serotonergic neurons differing in their gene expression and distribution in the DR (Huang et al., 2019). The neurons from two of these subtypes are mainly located in the DRVL and specifically express Bcl11b [B-cell leukemia/lymphoma 11B (also called Ctip2)]. We analyzed the expression of BCL11B in the serotonergic neurons. In adult wild-type animals, we found BCL11B protein to be weakly expressed in the DR area and colocalized with 5-HT in only a few cells (data not shown). Instead, at E18.5, we detected stronger BCL11B expression in the DR area, allowing us to analyze the DRD and DRVL regions. In the control embryos, we found

\section{$\leftarrow$}

$Z f p m 1^{C K O}$ animals at E18.5. $N=4$ embryos/genotype-positive cells were counted per section (four sections per animal), and the average cell number was calculated per animal. Data are visualized as the mean with the SD [independent-samples two-tailed $t$ test: DRD (5-HT:

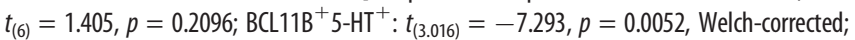
percentage of $\left.\mathrm{BCL11B}^{+} 5-\mathrm{HT}^{+}: t_{(6)}=22.61, p<0.0001\right)$; DRVL (5-HT: $t_{(6)}=13.28, p=$ $0.0001 ; \mathrm{BCL11B}^{+} 5-\mathrm{HT}^{+}: t_{(6)}=4.709, p=0.0033$; percentage of $\mathrm{BCL11B}^{+} 5-\mathrm{HT}^{+}: t_{(6)}=$ $0.7545, p=0.4791]^{* *} p<0.01,{ }^{* * *} p<0.001,{ }^{* * * *} p<0.0001$.
BCL11B-expressing serotonergic neurons $\left(\mathrm{BCL}_{11 \mathrm{~B}}{ }^{+} 5-\mathrm{HT}^{+}\right)$in the DRVL subregion (mean $\pm \mathrm{SD}, 22.19 \pm 2.414$ ), while in the $Z f p m 1^{C K O}$ embryos the number of these cells in the DRVL had decreased (mean $\pm \mathrm{SD}, 10.13 \pm 0.857$; control vs $Z f p m 1^{C K O}$ : $t_{(6)}=4.709, p=0.0033$, independent-samples two-tailed $t$ test; Fig. 4D). In contrast, in the control embryos we found only few $\mathrm{BCL}_{11 \mathrm{~B}}{ }^{+} 5-\mathrm{HT}^{+}$neurons in the $\mathrm{DRD}$ area (mean $\pm \mathrm{SD}$, $3.00 \pm 0.2041)$, whereas the number of $\mathrm{BCL} 11 \mathrm{~B}^{+} 5-\mathrm{HT}^{+}$neurons in the DRD of $Z f p m 1^{C K O}$ embryos was increased (mean $\pm \mathrm{SD}$, $31.94 \pm 3.963$; control vs $Z f p m 1^{C K O}: t_{(3.016)}=-7.293, p=0.0052$, independent-samples two-tailed, Welch-corrected $t$ test; Fig. $4 D)$. These results suggest that in the $Z f p m 1^{C K O}$ animals the DRVL serotonergic neurons are generated but mostly fail to correctly position in the DRVL and are misplaced to the DRD region instead.

As Zfpm1, like Gata3, is expressed in the adult DR serotonergic neurons (Fig. 1A), ZFPM1 could cooperate with GATA3 to maintain the serotonergic identity (Liu et al., 2010). In disagreement with this hypothesis, we did not observe changes in the amount of $5-\mathrm{HT}^{+}$neurons or the expression of Slc6a4, Slc17a8, or Pet1 in the Zfpm $1^{C K O}$ animals (except in the DRVL; Fig. $4 A$ ), suggesting that GATA3 works independent of ZFPM1 to maintain the serotonergic neuron-specific gene expression in the adult DR.

\section{Serotonin levels and density of serotonergic fibers are decreased in anterior brain regions of $Z \mathrm{fpm} 1^{\mathrm{CKO}}$ mutants}

The serotonergic neurons located at different parts of DR have distinct projection targets in the rostral brain and are differently involved in the regulation of behavior (Lacroix et al., 2000; Waselus et al., 2011; Spiacci et al., 2012; Parfitt et al., 2017; Ren et al., 2018). To analyze the possible changes of serotonin concentrations in the rostral brain areas in the $Z f p m 1^{C K O}$ animals, we dissected the PFC, HPC, and dMB of adult female mice (control, $\left.N=10 ; Z f p m 1^{C K O}, N=7\right)$ and measured neurotransmitter concentrations by HPLC. In the $Z f p m 1^{C K O}$ animals, we detected lower levels of serotonin in the PFC and HPC (PFC: $U=11, p=$ 0.0185; HPC: $U=0, p<0.0001$, independent-samples two-tailed Mann-Whitney $U$ test $)$, but not in the $\mathrm{dMB}(U=22, p=0.2295$, independent-samples two-tailed Mann-Whitney $U$ test; Fig. $5 \mathrm{~A}$ ). Additionally, the concentration of serotonin metabolite 5hydroxyindoleacetic acid (5-HIAA) was decreased in the HPC of $Z f p m 1^{C K O}$ mice, but remained comparable in the PFC and dMB (PFC: $U=27, p=0.4747$; HPC: $U=1, p=0.0002$; dMB: $U=30$, $p=0.6691$; independent-samples two-tailed Mann-Whitney $U$ test; Fig. 5A). We also analyzed the quantity of noradrenaline, dopamine and its metabolites DOPAC and HVA in these brain areas. We observed a decrease of dopamine in the HPC and an increase in the dMB of $Z f p m 1^{C K O}$ animals (HPC: $t_{(12,15)}=2.430$, $p=0.0315$; independent-samples two-tailed $t$ test; dMB: $\mathrm{U}=6$, $p=0.0031$, independent-samples two-tailed Mann-Whitney $U$ test), but did not detect any changes in the concentration of its metabolites or noradrenaline in these structures in the $Z \mathrm{fpm} 1^{\text {CKO }}$ animals (Table 1).

To explore whether the observed reduction in serotonin levels in HPC reflects diminished serotonergic fiber innervation, we quantified the density of 5-HT-labeled projections in the dorsal and ventral HPC regions. In addition, we evaluated the 5-HT fiber densities in the SC, dorsal lateral geniculate nucleus (dLGN), and the basolateral nucleus of amygdala (BLA), as these regions are major DRVL or DRD projection targets (Muzerelle et al., 2016; Ren et al., 2018). As expected, Zfpm $1^{\text {CKO }}$ animals showed significant reduction of 5-HT fiber densities in the dorsal and ventral HPC, the dLGN, and the SC regions (SC: $t_{(6)}=8.628$, $p=0.0001$; ventral HPC: $t_{(6)}=3.821, p=0.0088$; dorsal HPC: $t_{(6)}=$ 
A
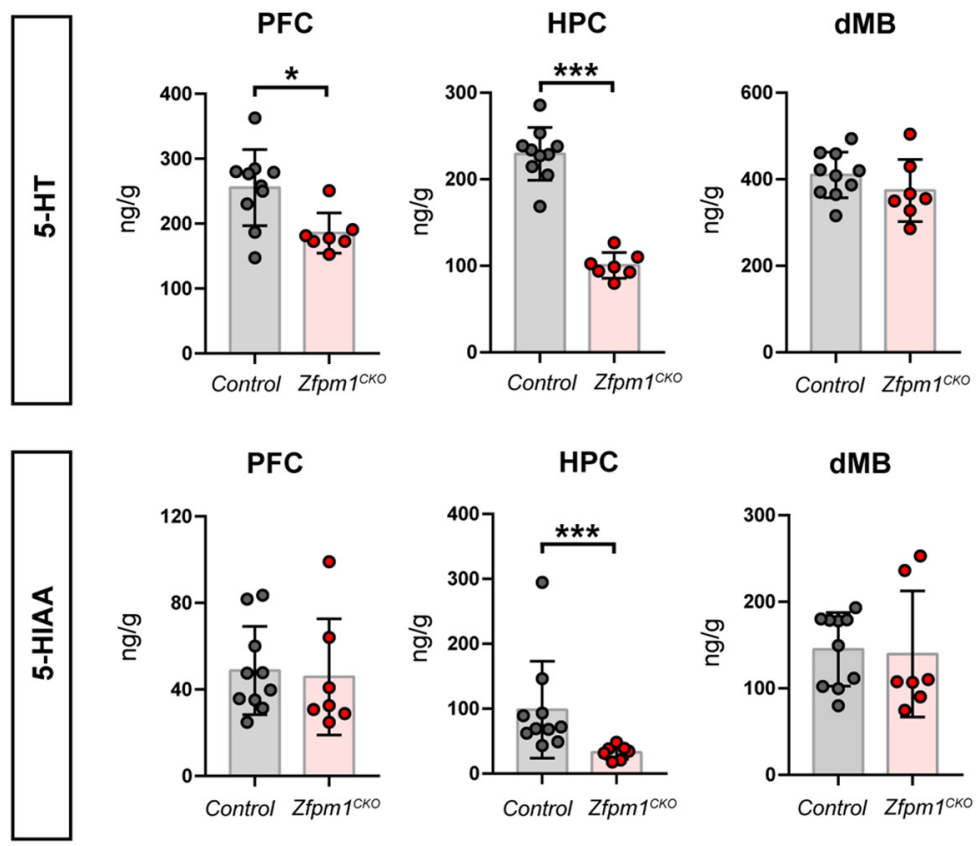

B
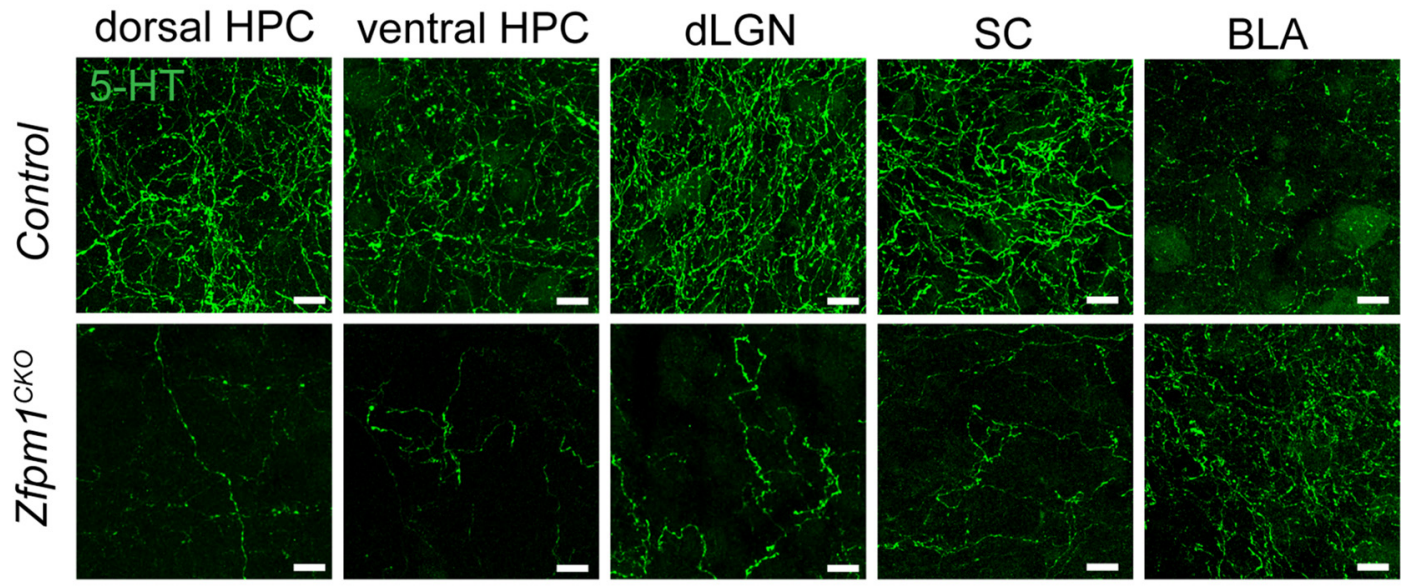

dorsal HPC

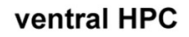

dLGN

SC

BLA
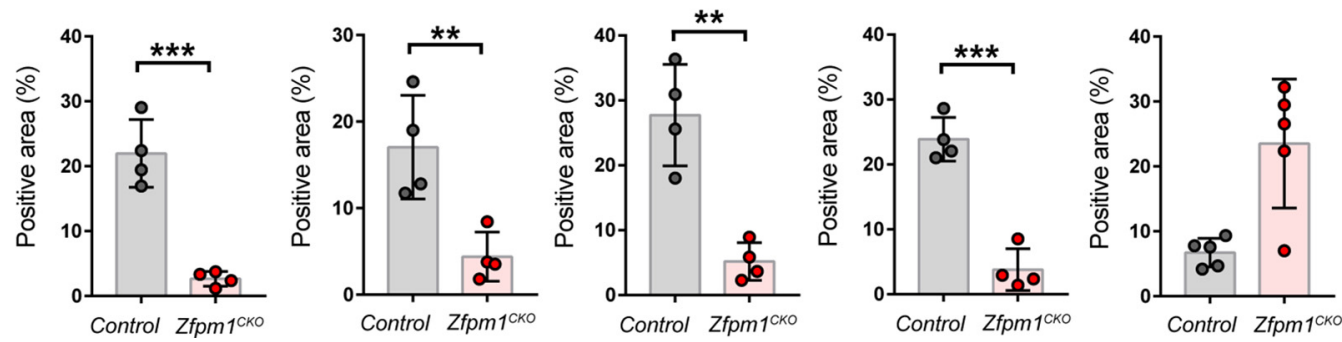

Figure 5. Zfpm $7^{C K O}$ mice have a lower concentration of 5-HT and reduced serotonergic fiber density in rostral brain structures. $A$, HPLC analysis of 5-HT and 5-HIAA (ng/g) concentration in the PFC, $\mathrm{HPC}$, and dMB in adult control $(N=10)$ and $Z \mathrm{Zfpm}^{\mathrm{CKO}}(\mathrm{N}=7)$ female mice. Data are visualized as the mean with the SD. 5-HT (independent-samples two-tailed Mann-Whitney $U$ test; PFC: $U=11, p=$ 0.0185; HPC: $U=0, p=0.0001$; dMB: $U=22, p=0.2295$ ); and 5-HIAA (independent-samples two-tailed Mann-Whitney $U$ test; PFC: $U=27, p=0.4747 ;$ HPC: $U=1, p=0.0002 ; \mathrm{dMB}: U=30, p=$ 0.6691). $B$, Distribution of $5-\mathrm{HT}^{+}$fibers in the dorsal and ventral HPC, dLGN, SC, and BLA regions of control and Zfpm $7^{C K O}$ adult mice. Scale bars, $10 \mu \mathrm{m}$. Quantification of 5-HT fibers in control and $Z \mathrm{ffpm} 7^{\mathrm{CKO}}$ mice. $N=4-5$ animals/genotype. Data are visualized as the mean with the SD (independent-samples two-tailed $t$ test; dorsal HPC: $t_{(6)}=7.223, p=0.0004$; ventral HPC: $t_{(6)}=3.821, p=$ 0.0088; dLGN: $t_{(6)}=5.41, p=0.0016 ; S C: t_{(6)}=8.628, p=0.0001$; independent-samples two-tailed Mann-Whitney $U$ test; BLA: $\left.U=3, p=0.0556\right) .{ }^{*} p<0.05,{ }^{* *} p<0.01,{ }^{* * *} p<0.001$.

7.223, $p=0.0004$; dLGN: $t_{(6)}=5.41, p=0.0016$, independent-samples two-tailed $t$ test; Fig. $5 B)$. On the contrary, Zfpm $1^{C K O}$ animals showed a trend of increased 5-HT fiber density in the BLA region (BLA: $U=3, p=0.0556$, independent-samples two-tailed Mann-
Whitney $U$ test; Fig. $5 B$ ). Altogether, we found that $Z f p m 1^{C K O}$ animals have lower concentrations of serotonin and reduced serotonergic fiber density in several anterior brain regions, with the notable exception of the amygdala. 
Table 1. Analysis of dopamine, DOPAC, HVA, and noradrenaline concentrations in the PFC, hippocampus, and dorsal midbrain of $Z \mathrm{fpm}^{\mathrm{CKO}}$ animals

\begin{tabular}{|c|c|c|c|}
\hline & Groups, ng/g (me & & \\
\hline & Control $(N=10)$ & $Z f p m 7^{C K O}(N=7)$ & $p$ Value \\
\hline PFC & & & \\
\hline DA & $697.19 / 479.63$ & $594.29 / 529.89$ & 0.6009 \\
\hline DOPAC & 274.91/113.75 & 197.20/118.17 & 0.1924 \\
\hline HVA & $59.79 / 17.08$ & $52.73 / 20.36$ & 0.6691 \\
\hline NA & $356.19 / 63.48$ & $357.24 / 60.71$ & 0.9731 \\
\hline HPC & & & \\
\hline DA & $30.70 / 16.11$ & $17.17 / 5.94$ & $0.0315^{*}$ \\
\hline DOPAC & ND & ND & ND \\
\hline HVA & ND & ND & ND \\
\hline NA & $468.72 / 56.28$ & $470.13 / 54.57$ & 0.9597 \\
\hline$d M B$ & & & \\
\hline DA & $124.28 / 16.34$ & $154.03 / 19.34$ & $0.0031^{*}$ \\
\hline DOPAC & $75.00 / 18.57$ & $87.96 / 14.49$ & 0.1440 \\
\hline HVA & $9.90 / / 2.61$ & $13.40 / 10.37$ & 0.7921 \\
\hline NA & $618.19 / 55.72$ & $619.41 / 38.35$ & 0.9606 \\
\hline
\end{tabular}

HPLC analysis of dopamine (DA), DOPAC, HVA, and noradrenaline (NA; $\mathrm{ng} / \mathrm{g}$ ) concentration in the PFC, HPC, and $\mathrm{dMB}$ in adult control and $\mathrm{Zfpm} 7^{\mathrm{CKO}}$ female mice (the number of animals used in the analysis is shown in the brackets). independent-samples two-tailed Mann-Whitney $U$ test or independent-samples two-tailed $t$ test was used and mean with the SD is shown. ND, Not determined. ${ }^{*} p<0.05$.

\section{Zfpm $1^{C K O}$ animals display increased anxiety-like behavior} but normal contextual discrimination

Serotonergic signaling in the amygdala, PFC, and HPC is involved in the regulation of memory and anxiety-related behavior (Tu et al., 2014; Ren et al., 2018). Therefore, we performed EPM, NOR, and CFC tests with the $Z f p m 1^{C K O}$ animals. In the EPM test, both male (control, $N=4 ; Z f p m 1^{C K O}, N=6$ ) and female (control, $\left.N=10 ; Z f p m 1^{C K O}, N=7\right)$ mice displayed an anxiety-like phenotype (genotype: $F_{(1,23)}=12.99, p=0.0015$; sex: $F_{(1,23)}=0.08,863, p=0.7686$; Fig. $\left.6 A\right)$. Additionally, both sexes displayed a neophobic phenotype in the NOR test (genotype: $F_{(1,22)}=82.14, p<0.0001$; sex: $F_{(1,22)}=0.3178, p=0.5786$; Fig. $6 B)$. The female $Z f p m 1^{C K O}(N=6)$ animals (males were not tested) displayed normal contextual memory when compared with the control $(N=11)$ animals in the contextual discrimination task, but a decrease in total activity (genotype: $F_{(1,15)}=$ 4.468, $p=0.0517$; trial: $F_{(1,15)}=32.67, p<0.0001$; interaction: $F_{(1,15)}=0.9497, p=0.3452$; Fig. $\left.6 C\right)$.

\section{Zfpm $1^{\text {CKO }}$ animals have increased contextual fear memory}

Under the control of serotonin signaling, the amygdala, PFC, and HPC also regulate associative fear learning during CFC (Phillips and LeDoux, 1992; Dai et al., 2008; Zelikowsky et al., 2013; Senn et al., 2014; Johnson et al., 2015; Xu et al., 2016). Therefore, we analyzed fear learning of the $Z \mathrm{fpm} 1^{\mathrm{CKO}}$ mice using the CFC paradigm. For males, we observed a genotype effect $\left(F_{(1,8)}=16.64, p=0.0035\right)$ and a trend interaction between genotype and trial $\left(F_{(3,24)}=2.444, p=0.0886\right)$. However, this effect appeared biased by the fact that control animals were not conditioned in the paradigm used, as suggested by the lack of difference in freezing time between conditioning and first extinction (ext1) trial for this group (Fig. 6D). For females, we observed a genotype effect $\left(F_{(1,15)}=18.52, p=0.0006\right)$ but no interaction between the factors $\left(F_{(3,45)}=1.074, p=0.3697\right)$. Female $Z f p m 1^{C K O}$ mice showed increased freezing (percentage of total time) on the subsequent postshock days compared with the control. These results show that the female $Z f p m 1^{C K O}$ mice are able to be conditioned but have increased contextual fear memory. After correcting for the total activity in the 5 min pretest session immediately before the delivery of the shocks, the overall genotype effect persisted across the trials $\left(F_{(1,22)}=9.865, p=0.0047\right)$.

\section{Chronic fluoxetine treatment reverses the increased contextual fear memory in the $\mathrm{Zfpm} 1^{\mathrm{CKO}}$ mice}

Selective serotonin reuptake inhibitors (SSRIs), such as fluoxetine, are used as antidepressants that increase the serotonin level in the synapses by inhibiting its reuptake into presynaptic serotonergic neurons via serotonin transporter SLC6A4 (Vaswani et al., 2003). Previous experiments in mice demonstrated fluoxetine treatment ( 3 weeks) facilitates fear erasure (Karpova et al., 2011; Sanders and Mayford, 2016; Yohn et al., 2018). Thus, control and $Z f p m 1^{C K O}$ female animals (only females were used as they were conditioned normally in the CFC experiment; see above) received fluoxetine $(15 \mathrm{mg} / \mathrm{kg} / \mathrm{d}$ in drinking water) for 3 weeks. Afterward, the CFC was conducted and FR was performed 1 week later while the fluoxetine treatment continued (Fig. 7A). Fluoxetine administration lowered the freezing of the control (flx) animals only at the FR stage compared with the control (ctrl) group (interaction: $F_{(4,120)}=3.456, p=0.0104$; Fig. $5 B$ ). On the other hand, fluoxetine treatment lowered the freezing of $Z f p m 1^{C K O}$ animals at all stages of CFC (treatment: $F_{(1,30)}=8.435$, $p=0.0068$; trial: $F_{(4,120)}=10.84, p<0.0001$; interaction: $F_{(4,120)}=2.378, p=0.0556$; Fig. $\left.7 A\right)$. These results show that chronic fluoxetine treatment reduces the increased contextual fear memory seen in the $Z f p m 1^{C K O}$ animals to normal levels.

We also analyzed how acute administration of fluoxetine $\left(15 \mathrm{mg} / \mathrm{kg}\right.$ ) affects the immobility (s) of control and $Z \mathrm{fpm} 1^{\mathrm{CKO}}$ in the FST. Adult male control (10 ctrl, 7 fluoxetine) and $Z f p m 1^{C K O}$ (10 ctrl, 9 fluoxetine) animals received intraperitoneal injection of PBS or fluoxetine $30 \mathrm{~min}$ before the FST. Acute fluoxetine treatment reduced the immobility of both control (flx) and $Z f p m 1^{C K O}$ (flx) animals $\left(F_{(1,33)}=91.89, p<0.0001\right.$; Fig. $\left.7 B\right)$, suggesting that $Z f p m 1^{C K O}$ and control animals respond similarly to fluoxetine animals in the FST.

\section{Discussion}

The DR is a heterogeneous serotonergic nucleus divided into several anatomic subregions and neuronal subtypes that are still incompletely understood but appear important for distinct aspects of behavioral regulation (Hale and Lowry, 2011; Ren et al., 2018; Huang et al., 2019). The TFs GATA2 and GATA3, expressed in serotonergic neuron precursors soon after their cell cycle exit, are important for the early differentiation of the serotonergic neurons in the r1 (Craven et al., 2004; Haugas et al., 2016). GATA cofactors, including ZFPM1, are involved in guiding the differentiation of GATA-dependent cell types in other developmental contexts. Here, we investigated the role of ZFPM1 in the neuronal differentiation in the ventral $\mathrm{rl}$ and the DR development. We show that ZFPM1 is dispensable for the acquisition of the serotonergic identity in the early precursors, but is required for the normal development of the DRVL subpopulation of serotonergic neurons, serotonergic innervation, and serotonin levels in the rostral brain, as well as anxiety-like behavior.

\section{Zfpm1 regulates the development of anatomically distinct subregions of the DR}

In the embryonic $Z f p m 1^{C K O}$ brain, we detected no changes in the number of early serotonergic precursors, suggesting that GATA2 and GATA3 function independently of ZFPM1 to determine serotonergic neuron-specific gene expression. In contrast, the analysis of DR in the $Z f p m 1$ mutants at later stages revealed a reduction of DRVL serotonergic neurons but an increased 
A

elevated plus maze - EPM

Control

Zfpm $1^{\text {cko }}$

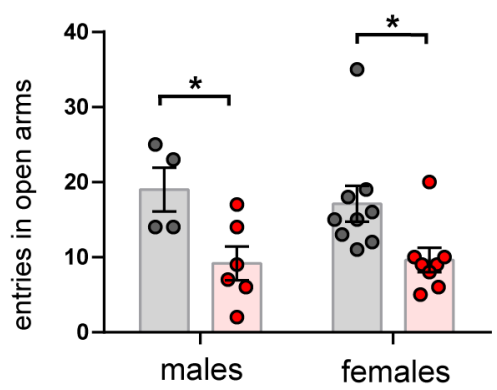

C

contextual memory
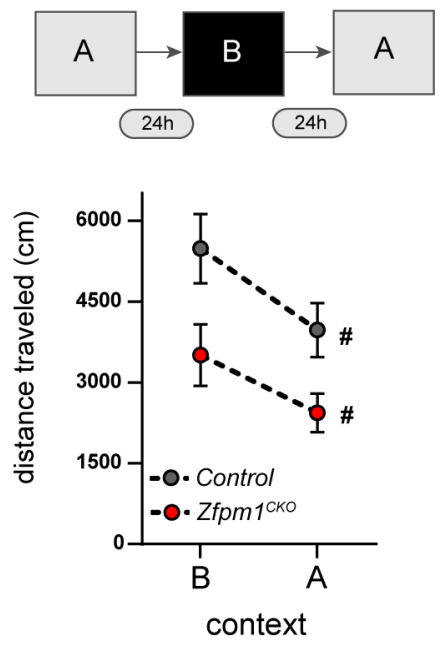

B

\section{novel object recognition - NOR}
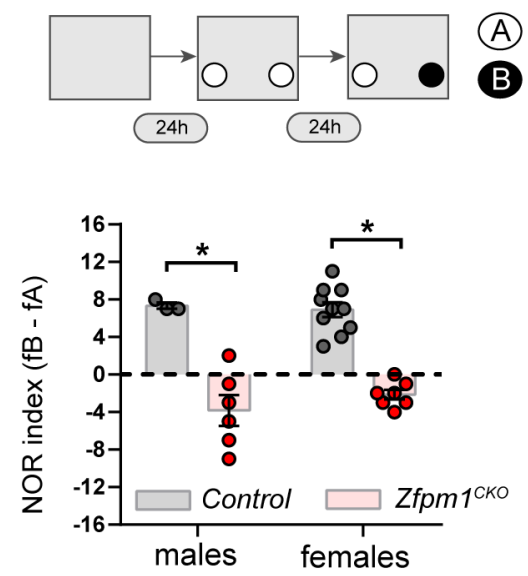

D

contextual fear conditioning

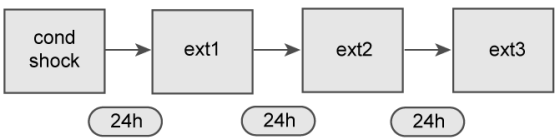

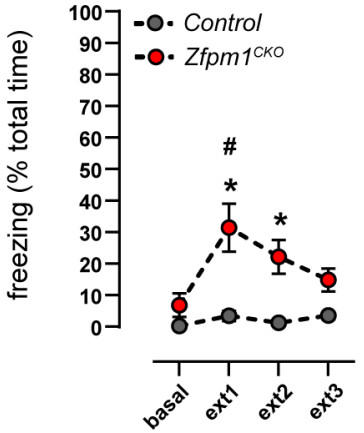

males

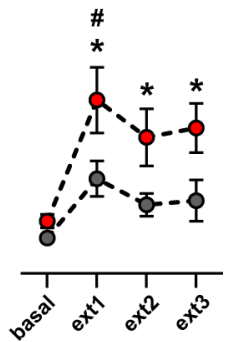

females

Figure 6. $Z \mathrm{fpm} 7^{\mathrm{CKO}}$ mice display increased anxiety-like behavior and increased fear memory. $\boldsymbol{A}$, Entries of adult $Z \mathrm{fpm} 7^{\mathrm{CKO}}$ (6 males, 7 females) and control (4 males, $\left.10 \mathrm{females}\right)$ mice to the open arm in the EPM test. Data are visualized as the mean with the SEM. Two-way ANOVA showing significant main effect of genotype $\left(F_{(1,23)}=12.99, p=0.0039\right)$ but not sex $\left(F_{(1,23)}=\right.$ $0.08863, p=0.7686) .{ }^{*} p<0.05$. B , Interaction of adult Zfpm ${ }^{\text {KKO }}$ (6 males, 7 females) and control (4 males, 10 females) mice with the novel object compared with the old object (NOR index) in the NOR test. Data are visualized as the mean with the SEM. Two-way ANOVA showing a significant main effect of genotype $\left(F_{(1,22)}=82.14, p<0.0001\right)$ but not sex $\left(F_{(1,22)}=0.3178, p=0.5786\right)$. ${ }^{*} p<0.05$. C, Contextual memory of adult female Zfpm7 ${ }^{\mathrm{CKO}}(N=6)$ and control $(N=11)$ mice analyzed by distance traveled $(\mathrm{cm})$. Data are visualized as the mean with the SEM. Two-way repeated ANOVA with multiple comparison (Fisher's LSD post hoc test), showing reduced total activity in the A context (on the third day) compared with context $B$ in both control $(p<0.0001)$ and Zfpm $7^{K O}$ ( $p=$ $0.01)$ animals. ${ }^{\#} p 0.05$ compared to distance traveled in context B. D, Increased fear memory in the CFC (increased freezing percentage of total time) of adult Zffpm $7^{\mathrm{CKO}}$ mice (6 males, 7 females) compared with controls ( 4 males, 10 females). Data are visualized as a mean with the SEM. Two-way repeated ANOVA showing the main effect of genotype in males $\left(F_{(1,8)}=16.64, p=0.0035\right)$ and females $\left(F_{(1,15)}=18.52, p=0.0006\right) .{ }^{\#} p<0.05$ compared to basal freezing, ${ }^{*} p<0.05$ compared to Control at the same time point.

number of serotonergic neurons in the DRD. This phenotype could be caused by a differentiation defect, resulting in an increased number of DRD neurons at the expense of DRVL neurons. Another possibility is a positioning defect, leading to a misplacement of DRVL neurons in the DRD subregion. Consistent with the latter hypothesis, we found an increased number of neurons positive for the DRVL marker BCL11B in the DRD of $Z f p m 1^{C K O}$ animals (Huang et al., 2019). The function of ZFPM1 in the developing serotonergic neurons may be related to the function of ZFPM2 in the late subtype specification and axonal guidance of the developing corticothalamic neurons (Galazo et al., 2016). Interestingly, ZFPM2 was shown to be important for the repression of BCL11B expression in the corticothalamic neurons.
Although the migratory patterns of serotonergic neuron subtypes remain poorly understood, analyses of some mouse mutant models have provided clues to these processes. A phenotype similar to the $Z \mathrm{fpml} \mathrm{I}^{\mathrm{CKO}}$ animals was shown in mutant mice where Reelin signaling was disrupted (Shehabeldin et al., 2018). The inactivation of the extracellular protein RELN (Reelin), its adaptor protein DAB1 (disabled homolog 1) or coinactivation of its receptors VLDLR (very low-density lipoprotein receptor) and LRP8 [low-density lipoprotein receptor-related protein 8 (ApoER2)] caused a reduction of DRVL neurons, while the number of serotonergic neurons in the DRD was increased (Shehabeldin et al., 2018). However, regional subtype-specific markers, such as BCL11B, were not analyzed in this study. Future studies should address whether components of the RELN pathway or other 
A

\section{contextual fear conditioning after chronic fluoxetine}
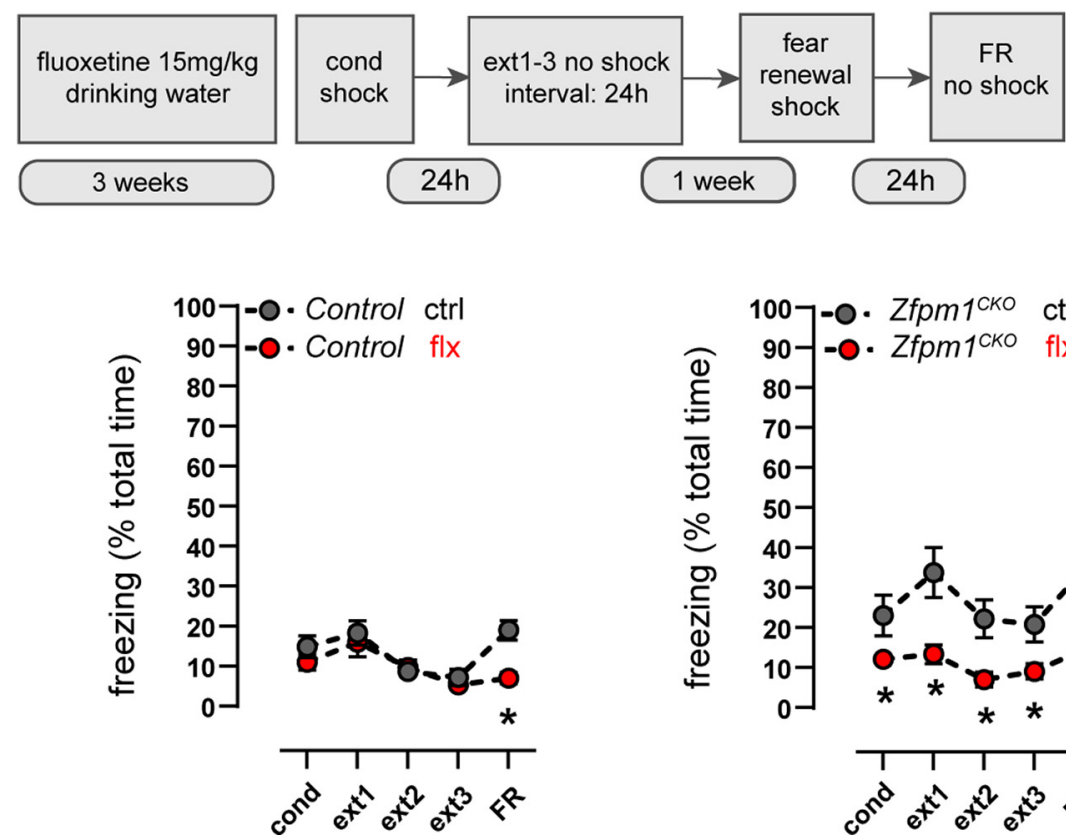

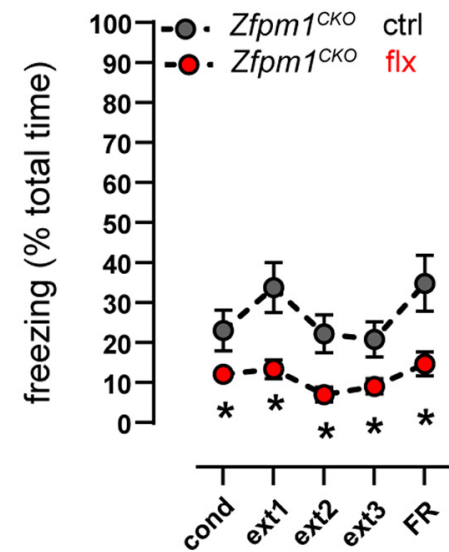

B

\section{forced swim test (FST)}
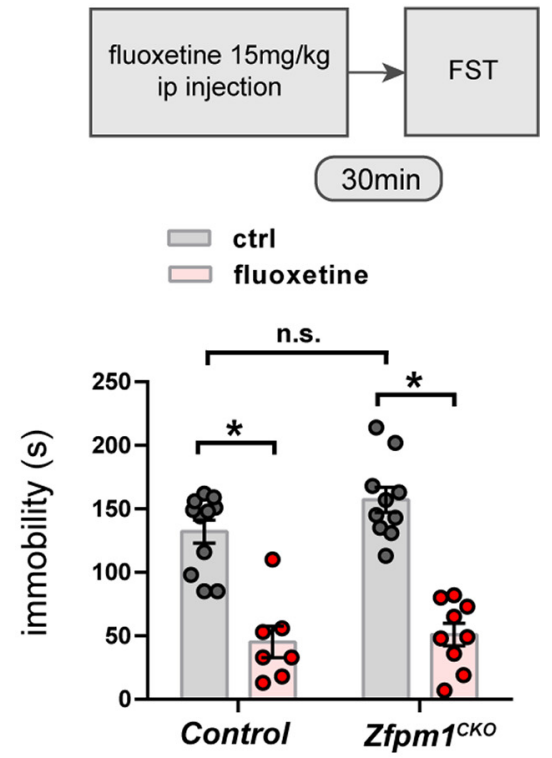

Figure 7. Chronic fluoxetine treatment reduces freezing in the contextual fear conditioning in the Zfpm $1^{\mathrm{CKO}}$ mice. $A$, Top, Schematic overview of the experimental setup. Adult female control and $Z f p m 1^{C K O}$ animals were divided into four groups: control (ctrl, $\left.N=16\right)$ and $Z f p m 1^{C K O}$ ( $\left.c t r l, N=16\right)$ groups received regular drinking water, while control (flx, $N=12$ ) and $Z f p m 1^{C K O}$ (flx, $N=15)$ groups received fluoxetine $(15 \mathrm{mg} / \mathrm{kg}$ ) in their drinking water for 3 weeks after which CFC with fear reinstatement was conducted. From the fear reinstatement only the freezing on the second day (FR) is shown. Data are visualized as a mean with the SEM. Two-way repeated ANOVA. Left, Decreased freezing (percentage of total time) of the control (flx) group compared with the control (ctrl) group at FR stage (interaction: $F_{(4,120)}=3.456, p=0.0104$ ). Right, Decreased freezing of Zfpm ${ }^{C K O}$ (flx) animals compared with Zfpm $1^{C K O}$ (ctrl) group at all stages of CFC (treatment: $F_{(1,30)}=8.435, p=0.0068$; trial: $F_{(4,120)}=10.84, p<0.0001$; interaction: $\left.F_{(4,120)}=2.378, p=0.0556\right)$. ${ }^{*} p<0.05$. B, Acute fluoxetine treatment $(15$ mg/kg) decreases immobility (s) of male control and $Z f p m 1^{C K O}$ animals in the FST. Adult male control and $Z f p m 1^{C K O}$ animals where divided into four groups: control $(N=10)$ and $Z f p m 1^{C K O}(\mathrm{~N}=10)$ groups (ctrl) received intraperitoneal injection of PBS, whereas control $(N=7)$ and $Z f p m 7^{C K O}(N=9)$ groups (flx) received intraperitoneal injection of fluoxetine (15 mg/kg) $30 \mathrm{~min}$ before FST. Two-way ANOVA, showing the main effect of fluoxetine $\left(F_{(1,33)}=91.89, p<0.0001\right)$ but not genotype $\left(F_{(1,33)}=2.349, p=0.1349\right)$ on immobility. ${ }^{*} p<0.05$, n.s. not significant.

cell adhesion molecules are affected by the absence of ZFPM1. In contrast to ZFPM1 and RELN, EN1 and EN2 are required in the postmitotic serotonergic neuron precursors for their migration toward the midline (Fox and Deneris, 2012). Thus, as a TF activated after cell cycle exit, ZFPM1 may repress transcriptional programs, which promote the medial migration of the serotonergic neuron precursors.

\section{$Z f p m 1^{C K O}$ animals display increased anxiety-like behavior} and contextual fear memory

Imbalance of the serotonergic neurons in different DR subregions may have implications on behavior. The DRD projects to the amygdala and facilitates anxiety-like behavior in mice in the EPM, whereas the activation of DRV, which innervates the orbitofrontal cortex (region of PFC), reduces the immobility in the FST, showing decreased depression-like behavior (Ren et al., 2018). Earlier studies also suggest that serotonin has an anxiogenic effect in the amygdala (Andersen and Teicher, 1999; Johnson et al., 2015) and a anxiolytic effect in other regions, including the PFC and HPC (Tu et al., 2014; Padilla-Coreano et al., 2016; Parfitt et al., 2017; Jimenez et al., 2018). Therefore, the increased anxiety-like behavior of $Z \mathrm{fpm} 1^{\mathrm{CKO}}$ animals could be caused by altered balance of serotonin signaling in the brain, resulting from decreased serotonin levels in several brain areas, such as the PFC, HPC, thalamus, and SC, concomitant with continued high serotonergic input to the amygdala from the DRD containing ectopic DRVL-like serotonergic neurons. However, additional studies are needed to confirm the projectional targets of these ectopic neurons in the DRD. In addition to the DRVL projection targets, the thalamus (dLGN), and SC, the $Z f p m 1^{C K O}$ animals exhibited lower serotonergic innervation and serotonin levels in the HPC and PFC, which do not receive abundant DRVL projections (Muzerelle et al., 2016). Therefore, in addition to the DRVL precursor migration, loss of ZFPM1 function may also affect axon growth in other DR and MR serotonergic neuron subtypes that are derived from the r1 (Jensen et al., 2008). Regarding their serotonergic neuron projection patterns and behavioral phenotype, the $Z \mathrm{fpm} 1^{\mathrm{CKO}}$ mice resemble the Pet $1 \mathrm{mu}-$ tant mice, which also display broadly reduced brain serotonin levels, concomitant with maintained serotonergic projections to the BLA, and changes in their anxiety behavior and memory function (Kiyasova et al., 2011; Fernandez et al., 2017). We found Pet1 still expressed in the $Z f p m 1^{C K O}$ mice, suggesting that the changes in the serotonergic innervation of the $Z f p m 1^{C K O}$ mutants are not because of a loss of Pet 1 activity. Interestingly, in addition to being resistant to the loss of Zfpm 1 and Pet 1 , the serotonergic neurons projecting to the BLA have excitability and membrane properties distinct from the ones projecting to the HPC and PFC (Fernandez et al., 2016), and thus appear to represent a unique neuronal subset.

Amygdala, HPC, and PFC are also important in the acquisition, retrieval, and expression of contextual fear memories 
(Phillips and LeDoux, 1992; Senn et al., 2014; Xu et al., 2016). For example, Pet $1^{\text {Cre }}$; Lmx $1 b^{\text {floxfflox }}$ and also Pet ${ }^{\text {CreERT2 }} ;$ Rosa $26^{\text {DTA }}$ mice that exhibit global loss of serotonergic neurons in the brain and substantial decrease of serotonin concentration in HPC and cortex show elevated freezing in the CFC, indicating an increase in the retrieval of fearful memories (Dai et al., 2008; Song et al., 2016). In line with these studies, we also observed increased contextual fear memory in the $Z f p m 1^{C K O}$ animals. Interestingly, Pet1 ${ }^{\mathrm{Cre}}$; $L m \times 1 b^{\text {flox/flox }}$ and $\mathrm{Pet}^{\mathrm{CreERT2}_{2}}$;Rosa26 ${ }^{\mathrm{DTA}}$ mice show reduced anxiety-like behavior in the EPM, contrary to the Zfpm $1^{C K O}$ animals.

\section{$Z f p m 1^{C K O}$ animals are strongly responsive to fluoxetine}

Previously, chronic fluoxetine administration has been shown to decrease the freezing behavior in the CFC and in the fear renewal (Karpova et al., 2011; Sanders and Mayford, 2016). Similarly, chronic fluoxetine treatment significantly lowered the freezing of female $Z f p m 1^{C K O}$ animals to levels comparable to those of control animals in the CFC. Fluoxetine, like other SSRIs, acts as an antidepressant by inhibiting the reuptake of serotonin and prolonging serotonergic transmission (Vaswani et al., 2003). Therefore, the reduced freezing of $Z f p m 1^{C K O}$ animals observed after the chronic fluoxetine administration can be caused by the rise of serotonin levels in the synapses that opposes the diminished levels of serotonin in the HPC and PFC that we observed in the $Z f p m 1^{C K O}$ mutants. Our fluoxetine treatment experiments thus suggest that at least the increased freezing behavior of the $Z f p m 1^{C K O}$ mice is because of a hyposerotonergic, rather than a hyperserotonergic, defect.

\section{Conclusions}

Neuronal subtype-specific features may be defined during development by key TFs and their cofactors. Defects in these processes may predispose neurodevelopmental psychiatric disease. We show that inactivation ZFPM1, a cofactor of GATA TFs high in the hierarchy of determination of the serotonergic identity, results in specific defects in the development of serotonergic neuron subtypes in the DR. This results in increased anxiety-like behavior and increased contextual fear memory that is highly responsive to treatment with antidepressant fluoxetine.

\section{References}

Achim K, Peltopuro P, Lahti L, Li J, Salminen M, Partanen J (2012) Distinct developmental origins and regulatory mechanisms for GABAergic neurons associated with dopaminergic nuclei in the ventral mesodiencephalic region. Development 139:2360-2370.

Airavaara M, Mijatovic J, Vihavainen T, Piepponen TP, Saarma M, Ahtee L (2006) In heterozygous GDNF knockout mice the response of striatal dopaminergic system to acute morphine is altered. Synapse 59:321-329.

Ampuero E, Stehberg J, Gonzalez D, Besser N, Ferrero M, Diaz-Veliz G, Wyneken U, Rubio FJ (2013) Repetitive fluoxetine treatment affects long-term memories but not learning. Behav Brain Res 247:92-100.

Andersen SL, Teicher MH (1999) Serotonin laterality in amygdala predicts performance in the elevated plus maze in rats. Neuroreport 10:34973500.

Beuling E, Bosse T, aan de Kerk DJ, Piaseckyj CM, Fujiwara Y, Katz SG, Orkin SH, Grand RJ, Krasinski SD (2008) GATA4 mediates gene repression in the mature mouse small intestine through interactions with friend of GATA (FOG) cofactors. Dev Biol 322:179-189.

Carobrez AP, Bertoglio LJ (2005) Ethological and temporal analyses of anxiety-like behavior: the elevated plus-maze model 20 years on. Neurosci Biobehav Rev 29:1193-1205.

Chlon TM, Doré LC, Crispino JD (2012) Cofactor-mediated restriction of GATA-1 chromatin occupancy coordinates lineage-specific gene expression. Mol Cell 47:608-621.
Craven SE, Lim KC, Ye W, Engel JD, de Sauvage F, Rosenthal A (2004) Gata2 specifies serotonergic neurons downstream of sonic hedgehog. Development 131:1165-1173.

Dai JX, Han HL, Tian M, Cao J, Xiu JB, Song NN, Huang Y, Xu TL, Ding YQ, Xu L (2008) Enhanced contextual fear memory in central serotonindeficient mice. Proc Natl Acad Sci U S A 105:11981-11986.

Ding YQ, Marklund U, Yuan WL, Yin J, Wegman L, Ericson J, Deneris E, Johnson RL, Chen ZF (2003) Lmxlb is essential for the development of serotonergic neurons. Nat Neurosci 6:933-938.

Fernandez SP, Cauli B, Cabezas C, Muzerelle A, Poncer JC, Gaspar P (2016) Multiscale single-cell analysis reveals unique phenotypes of raphe 5-HT neurons projecting to the forebrain. Brain Struct Funct 221:4007-4025.

Fernandez SP, Muzerelle A, Scotto-Lomassese S, Barik J, Gruart A, DelgadoGarcía JM, Gaspar P (2017) Constitutive and acquired serotonin deficiency alters memory and hippocampal synaptic plasticity. Neuropsychopharmacology 42:512-523.

Fox AH, Liew C, Holmes M, Kowalski K, Mackay J, Crossley M (1999) Transcriptional cofactors of the FOG family interact with GATA proteins by means of multiple zinc fingers. EMBO J 18:2812-2822.

Fox SR, Deneris ES (2012) Engrailed is required in maturing serotonin neurons to regulate the cytoarchitecture and survival of the dorsal raphe nucleus. J Neurosci 32:7832-7842.

Galazo MJ, Emsley JG, Macklis JD (2016) Corticothalamic projection neuron development beyond subtype specification: fog 2 and intersectional controls regulate intraclass neuronal diversity. Neuron 91:90-106.

Guimera J, Vogt Weisenhorn D, Echevarría D, Martínez S, Wurst W (2006) Molecular characterization, structure and developmental expression of Megane bHLH factor. Gene 377:65-76.

Hale MW, Lowry CA (2011) Functional topography of midbrain and pontine serotonergic systems: implications for synaptic regulation of serotonergic circuits. Psychopharmacology (Berl) 213:243-264.

Haugas M, Tikker L, Achim K, Salminen M, Partanen J (2016) Gata2 and Gata3 regulate the differentiation of serotonergic and glutamatergic neuron subtypes of the dorsal raphe. Development 143:4495-4508.

Hioki H, Nakamura H, Ma YF, Konno M, Hayakawa T, Nakamura KC, Fujiyama F, Kaneko T (2010) Vesicular glutamate transporter 3-expressing nonserotonergic projection neurons constitute a subregion in the rat midbrain raphe nuclei. J Comp Neurol 518:668-686.

Huang KW, Ochandarena NE, Philson AC, Hyun M, Birnbaum JE, Cicconet M, Sabatini BL (2019) Molecular and anatomical organization of the dorsal raphe nucleus. Elife 8:e46464.

Jensen P, Farago AF, Awatramani RB, Scott MM, Deneris ES, Dymecki SM (2008) Redefining the serotonergic system by genetic lineage. Nat Neurosci 11:417-419.

Jimenez JC, Su K, Goldberg AR, Luna VM, Biane JS, Ordek G, Zhou P, Ong SK, Wright MA, Zweifel L, Paninski L, Hen R, Kheirbek MA (2018) Anxiety cells in a hippocampal-hypothalamic circuit. Neuron 97:670683.e6.

Johnson P, Lowry C, Truitt W, Shekhar A (2008) Disruption of GABAergic tone in the dorsomedial hypothalamus attenuates responses in a subset of serotonergic neurons in the dorsal raphe nucleus following lactateinduced panic. J Psychopharmacol 22:642-652.

Johnson PL, Molosh A, Fitz SD, Arendt D, Deehan GA, Federici LM, Bernabe C, Engleman EA, Rodd ZA, Lowry CA, Shekhar A (2015) Pharmacological depletion of serotonin in the basolateral amygdala complex reduces anxiety and disrupts fear conditioning. Pharmacol Biochem Behav 138:174-179.

Kankaanpää A, Meririnne E, Ariniemi K, Seppälä T (2001) Oxalic acid stabilizes dopamine, serotonin, and their metabolites in automated liquid chromatography with electrochemical detection. J Chromatogr B Biomed Sci Appl 753:413-419.

Karpova NN, Pickenhagen A, Lindholm J, Tiraboschi E, Kulesskaya N, Agústsdóttir A, Antila H, Popova D, Akamine Y, Bahi A, Sullivan R, Hen R, Drew LJ, Castrén E (2011) Fear erasure in mice requires synergy between antidepressant drugs and extinction training. Science 334:17311734.

Katz SG, Williams A, Yang J, Fujiwara Y, Tsang AP, Epstein JA, Orkin SH (2003) Endothelial lineage-mediated loss of the GATA cofactor Friend of GATA 1 impairs cardiac development. Proc Natl Acad Sci U S A 100:14030-14035. 
Kimmel RA, Turnbull DH, Blanquet V, Wurst W, Loomis CA, Joyner AL (2000) Two lineage boundaries coordinate vertebrate apical ectodermal ridge formation. Genes Dev 14:1377-1389.

Kiyasova V, Fernandez SP, Laine J, Stankovski L, Muzerelle A, Doly S, Gaspar P (2011) A genetically defined morphologically and functionally unique subset of 5-HT neurons in the mouse raphe nuclei. J Neurosci 31:2756-2768.

Lacroix L, Spinelli S, Heidbreder CA, Feldon J (2000) Differential role of the medial and lateral prefrontal cortices in fear and anxiety. Behav Neurosci 114:1119-1130.

Lahti L, Haugas M, Tikker L, Airavaara M, Voutilainen MH, Anttila J, Kumar S, Inkinen C, Salminen M, Partanen J (2016) Differentiation and molecular heterogeneity of inhibitory and excitatory neurons associated with midbrain dopaminergic nuclei. Development 143:516-529.

Lein ES, Hawrylycz MJ, Ao N, Ayres M, Bensinger A, Bernard A, Boe AF, Boguski MS, Brockway KS, Byrnes EJ, Chen L, Chen L, Chen T-M, Chin MC, Chong J, Crook BE, Czaplinska A, Dang CN, Datta S, Dee NR, et al. (2007) Genome-wide atlas of gene expression in the adult mouse brain. Nature 445:168-176.

Lilleväli K, Matilainen T, Karis A, Salminen M (2004) Partially overlapping expression of Gata2 and Gata3 during inner ear development. Dev Dyn 231:775-781.

Liu C, Maejima T, Wyler SC, Casadesus G, Herlitze S, Deneris ES (2010) Pet1 is required across different stages of life to regulate serotonergic function. Nat Neurosci 13:1190-1198.

Lu JR, McKinsey TA, Xu H, Wang DZ, Richardson JA, Olson EN (1999) FOG-2, a heart- and brain-enriched cofactor for GATA transcription factors. Mol Cell Biol 19:4495-4502.

Manuylov NL, Smagulova FO, Tevosian SG (2007) Fog2 excision in mice leads to premature mammary gland involution and reduced Esr1 gene expression. Oncogene 26:5204-5213.

Miccio A, Wang Y, Hong W, Gregory GD, Wang H, Yu X, Choi JK, Shelat S, Tong W, Poncz M, Blobel GA (2010) NuRD mediates activating and repressive functions of GATA-1 and FOG-1 during blood development. EMBO J 29:442-456.

Morello F, Borshagovski D, Survila M, Tikker L, Sadik-Ogli S, Kirjavainen A, Estartus N, Knaapi L, Lahti L, Törönen P, Mazutis L, Delogu A, Salminen M, Achim K, Partanen J, (2020) Molecular fingerprint and developmental regulation of the tegmental GABAergic and glutamatergic neurons derived from the anterior hindbrain. Cell Reports 33:108268.

Muzerelle A, Scotto-Lomassese S, Bernard JF, Soiza-Reilly M, Gaspar P (2016) Conditional anterograde tracing reveals distinct targeting of individual serotonin cell groups (B5-B9) to the forebrain and brainstem. Brain Struct Funct 221:535-561.

Natarajan R, Forrester L, Chiaia NL, Yamamoto BK (2017) Chronic-stressinduced behavioral changes associated with subregion-selective serotonin cell death in the dorsal raphe. J Neurosci 37:6214-6223.

Okano HJ, Darnell RB (1997) A hierarchy of Hu RNA binding proteins in developing and adult neurons. J Neurosci 17:3024-3037.

Okaty BW, Freret ME, Rood BD, Brust RD, Hennessy ML, deBairos D, Kim JC, Cook MN, Dymecki SM (2015) Multi-scale molecular deconstruction of the serotonin neuron system. Neuron 88:774-791.

Padilla-Coreano N, Bolkan SS, Pierce GM, Blackman DR, Hardin WD, Garcia-Garcia AL, Spellman TJ, Gordon JA (2016) Direct ventral hippocampal-prefrontal input is required for anxiety-related neural activity and behavior. Neuron 89:857-866.

Pal S, Cantor AB, Johnson KD, Moran TB, Boyer ME, Orkin SH, Bresnick EH (2004) Coregulator-dependent facilitation of chromatin occupancy by GATA-1. Proc Natl Acad Sci U S A 101:980-985.

Parfitt GM, Nguyen R, Bang JY, Aqrabawi AJ, Tran MM, Seo DK, Richards BA, Kim JC (2017) Bidirectional control of anxiety-related behaviors in mice: role of inputs arising from the ventral hippocampus to the lateral septum and medial prefrontal cortex. Neuropsychopharmacology 42: $1715-1728$.

Paul ED, Johnson PL, Shekhar A, Lowry CA (2014) The Deakin/Graeff hypothesis: focus on serotonergic inhibition of panic. Neurosci Biobehav Rev 46:379-396.

Phillips RG, LeDoux JE (1992) Differential contribution of amygdala and hippocampus to cued and contextual fear conditioning. Behav Neurosci 106:274-285.
Qi J, Zhang S, Wang HL, Wang H, de Jesus Aceves Buendia J, Hoffman AF, Lupica CR, Seal RP, Morales M (2014) A glutamatergic reward input from the dorsal raphe to ventral tegmental area dopamine neurons. Nat Commun 5:5390.

Ren J, Friedmann D, Xiong J, Liu CD, Ferguson BR, Weerakkody T, DeLoach KE, Ran C, Pun A, Sun Y, Weissbourd B, Neve RL, Huguenard J, Horowitz MA, Luo L (2018) Anatomically defined and functionally distinct dorsal raphe serotonin sub-systems. Cell 175:472-487.e20.

Robert NM, Tremblay JJ, Viger RS (2002) Friend of GATA (FOG)-1 and FOG-2 differentially repress the GATA-dependent activity of multiple gonadal promoters. Endocrinology 143:3963-3973.

Sanders J, Mayford M (2016) Chronic fluoxetine dissociates contextual from auditory fear memory. Neurosci Lett 632:152-156.

Senn V, Wolff SB, Herry C, Grenier F, Ehrlich I, Gründemann J, Fadok JP, Müller C, Letzkus JJ, Lüthi A (2014) Long-range connectivity defines behavioral specificity of amygdala neurons. Neuron 81:428-437.

Shehabeldin R, Lutz D, Karsak M, Frotscher M, Krieglstein K, Sharaf A (2018) Reelin controls the positioning of brainstem serotonergic raphe neurons. PLoS One 13:e0200268.

Song NN, Xiu JB, Huang Y, Chen JY, Zhang L, Gutknecht L, Lesch KP, Li H, Ding YQ (2011) Adult raphe-specific deletion of $L m x 1 b$ leads to central serotonin deficiency. PLoS One 6:e15998.

Song NN, Jia YF, Zhang L, Zhang Q, Huang Y, Liu XZ, Hu L, Lan W, Chen L, Lesch KP, Chen X, Xu L, Ding YQ (2016) Reducing central serotonin in adulthood promotes hippocampal neurogenesis. Sci Rep 6:20338.

Spiacci A Jr, Coimbra NC, Zangrossi H Jr (2012) Differential involvement of dorsal raphe subnuclei in the regulation of anxiety- and panic-related defensive behaviors. Neuroscience 227:350-360.

Tevosian SG, Deconinck AE, Tanaka M, Schinke M, Litovsky SH, Izumo S, Fujiwara Y, Orkin SH (2000) FOG-2, a cofactor for GATA transcription factors, is essential for heart morphogenesis and development of coronary vessels from epicardium. Cell 101:729-739.

Tsang AP, Visvader JE, Turner CA, Fujiwara Y, Yu C, Weiss MJ, Crossley M, Orkin SH (1997) FOG, a multitype zinc finger protein, acts as a cofactor for transcription factor GATA-1 in erythroid and megakaryocytic differentiation. Cell 90:109-119.

Tsang AP, Fujiwara Y, Hom DB, Orkin SH (1998) Failure of megakaryopoiesis and arrested erythropoiesis in mice lacking the GATA-1 transcriptional cofactor FOG. Genes Dev 12:1176-1188.

Tu W, Cook A, Scholl JL, Mears M, Watt MJ, Renner KJ, Forster GL (2014) Serotonin in the ventral hippocampus modulates anxiety-like behavior during amphetamine withdrawal. Neuroscience 281:35-43.

Waselus M, Valentino RJ, Van Bockstaele EJ (2011) Collateralized dorsal raphe nucleus projections: a mechanism for the integration of diverse functions during stress. J Chem Neuroanat 41:266-280

Vaswani M, Linda FK, Ramesh S (2003) Role of selective serotonin reuptake inhibitors in psychiatric disorders: a comprehensive review. Prog Neuropsychopharmacol Biol Psychiatry 27:85-102.

Wyler SC, Spencer WC, Green NH, Rood BD, Crawford L, Craige C, Gresch P, McMahon DG, Beck SG, Deneris E (2016) Pet-1 switches transcriptional targets postnatally to regulate maturation of serotonin neuron excitability. J Neurosci 36:1758-1774.

Xu C, Krabbe S, Gründemann J, Botta P, Fadok JP, Osakada F, Saur D, Grewe BF, Schnitzer MJ, Callaway EM, Lüthi A (2016) Distinct hippocampal pathways mediate dissociable roles of context in memory retrieval. Cell 167:961-972.e16.

Yohn CN, Shifman S, Garino A, Diethorn E, Bokka L, Ashamalla SA, Samuels BA (2018) Fluoxetine effects on behavior and adult hippocampal neurogenesis in female C57BL/6J mice across the estrous cycle. Psychopharmacology (Berl) 237:1281-1290.

Zelikowsky M, Bissiere S, Hast TA, Bennett RZ, Abdipranoto A, Vissel B, Fanselow MS (2013) Prefrontal microcircuit underlies contextual learning after hippocampal loss. Proc Natl Acad Sci U S A 110:9938-9943.

Zhao ZQ, Scott M, Chiechio S, Wang JS, Renner KJ, Gereau RW, Johnson RL, Deneris ES, Chen ZF (2006) Lmxlb is required for maintenance of central serotonergic neurons and mice lacking central serotonergic system exhibit normal locomotor activity. J Neurosci 26:12781-12788. 